\title{
Security Analysts, Cash Flow Forecasts, and Turnover
}

\author{
Shailendra Pandit ${ }^{\mathrm{a}}$, Richard H. Willis ${ }^{\mathrm{b},{ }^{*}}$, Ling Zhou ${ }^{\mathrm{c}}$ \\ ${ }^{a}$ College of Business Administration, University of Illinois at Chicago, 601 South \\ Morgan Street, Chicago, IL 60607, United States \\ ${ }^{\mathrm{b}}$ Owen Graduate School of Management, Vanderbilt University, 40121 st Avenue South, \\ Nashville, TN 37203, United States \\ ${ }^{c}$ Anderson School of Management, The University of New Mexico, 1924 Las Lomas NE, \\ Albuquerque, NM 87131, United States
}

January 2012

Forthcoming in the International Journal of Forecasting

\begin{abstract}
We thank Xia Chen, Yonca Ertimur, Luke Froeb, Rob Hyndman (editor), Deen Kemsley, Doug Schroeder, Michael Smith, Stephen Stubben, an anonymous guest editor, two anonymous referees, and workshop participants at the 2008 American Accounting Association Annual Meeting, Arizona State University, Baruch College, George Mason University, Indiana University, Ohio State University, Rutgers University, Tulane University, the University of Illinois at Chicago, and Vanderbilt University for useful comments and discussions. We appreciate the financial support of the College of Business Administration at the University of the Illinois at Chicago, the Owen Graduate School of Management at Vanderbilt University, and the Anderson School of Management at the University of New Mexico. Analyst forecast data are from $\mathrm{I} / \mathrm{B} / \mathrm{E} / \mathrm{S}$. Errors or omissions are our responsibility.

*Corresponding author. Tel.: +1 615343 1050; Fax: +1 6153437177.

E-mail address: richard.willis@,owen.vanderbilt.edu (R.H. Willis).
\end{abstract}




\title{
Security Analysts, Cash Flow Forecasts, and Turnover
}

\begin{abstract}
We examine the relation between security analyst turnover and the relative accuracy of their annual earnings and cash flow forecasts. Controlling for self-selection in an analyst's decision to issue a cash flow forecast, we find that relatively more accurate earnings and cash flow forecasts reduce the probability of turnover. Relative earnings forecast accuracy decreases the probability of turnover more than relative cash flow forecast accuracy. We conduct two cross-sectional tests. We find that relative cash flow forecast accuracy is more important in the analyst's career outcome when cash flow forecasts are potentially more useful to investors. We find that relative cash flow forecast accuracy is more heavily weighted in the career outcome when the number of other analysts providing cash flow forecasts for the firm is larger. This finding is consistent with economic intuition that relative performance evaluation is more effective when larger groups of individuals are compared.
\end{abstract}

Keywords: Earnings forecasting; Econometric models; Evaluating forecasts; Forecasting profession; Monitoring forecasts 


\section{Introduction}

Traditionally, sell-side security analysts have provided earnings forecasts and stock recommendations for the firms they cover. More recently, analysts have included additional pieces of quantitative information, primarily cash flow forecasts and target prices, in their reports (see, e.g., Asquith, Mikhail, and Au, 2005; Bradshaw and Brown, 2006; Brav and Lehavy, 2003; DeFond and Hung, 2003). We investigate whether and when relative cash flow forecast accuracy affects analysts' career outcomes (measured by their turnover).

Examining the incentives of analysts to produce accurate cash flow forecasts is important for at least two reasons. First, understanding the effect of cash flow forecasts on analysts' job prospects allows us to contribute to the labor economics literature on how principals (brokerage employers) weight multiple output signals (earnings and cash flow forecasts) produced by agents (sell-side analysts). Second, if an analyst is not rewarded for issuing accurate cash flow forecasts, she is unlikely to exert effort to generate an accurate cash flow forecast. On the other hand, a brokerage house should compensate an analyst for publishing accurate cash flow forecasts if forecast accuracy helps differentiate the ability and effort of the analyst relative to others.

To investigate these issues, we examine whether the relative accuracy of cash flow forecasts is part of an analyst's performance evaluation. Because analyst compensation data are not publicly available, we use analyst turnover as our observable analyst performance evaluation metric. We believe that analysts are averse to turnover and investigate if analysts are more likely to experience turnover if their cash flow forecasts are less accurate relative to their peers, other analysts following the same firm 
in the same year. We control for analysts' relative earnings forecasting accuracy in our analyses because prior research (e.g., Hong and Kubik, 2003; Mikhail, Walther, and Willis, 1999) documents an inverse relation between relative earnings forecast accuracy and turnover.

First, we study the association between an analyst's relative cash flow forecast accuracy and turnover. Call, Chen, and Tong (2009) also provide evidence on the association between analyst turnover and relative cash flow forecast accuracy, but do not control for self-selection in an analyst's decision to issue cash flow forecasts. Selfselection bias can occur because it is unlikely that analysts choose randomly to release cash flow forecasts. An analyst's choice to issue a cash flow forecast is conditional on the perceived costs and benefits to her of providing a cash flow forecast in her report. Akin to an omitted variable, self-selection causes biased parameter estimates; the ordinary least squares estimator of the variance-covariance matrix is also biased, undermining statistical inference (Greene, 2005). Therefore, failure to control for selfselection in the forecasting task may alter the conclusions of prior work. To address these concerns, we model the cash flow forecast issuance decision and turnover using a seemingly unrelated bivariate probit estimation.

Based on a large sample of sell-side analysts providing earnings and cash flow forecasts (or earnings forecasts alone) during 1993 to 2005, we find an inverse relation between relative cash flow forecast accuracy and turnover. This inverse relation is weaker than that between relative earnings forecast accuracy and turnover. Thus, proficiency with forecasting cash flows appears to be important to an analyst's career outcome, but not as important as proficiency with forecasting earnings. Thus, the 
conclusions in Call, Chen, and Tong (2009) are not affected after controlling for selfselection. In our cash flow forecast issuance model, we find, similar to Ertimur and Stubben (2006), that analysts from larger brokerages and analysts who revise their earnings forecasts more frequently are more likely to issue cash flow forecasts. We also find that analysts who follow more firms and analysts who forecast closer to the annual earnings announcement date are more likely to issue cash flow forecasts.

Second, we examine cross-sectional variation in the weight placed on relative cash flow forecast accuracy, which has not been previously investigated. If brokerage houses are rational, they should reward analysts more for an accurate cash flow forecast when: (i) cash flow forecasts are more useful for investors; and (ii) cash flow forecasts are a more precise signal of analysts' effort or talent. These cross-sectional analyses yield insights into the efficiency with which brokerage firms evaluate analysts.

To examine the weight placed on cash flow forecast accuracy conditional on cash flow forecast usefulness to investors, we use DeFond and Hung's (2003) firm-level determinants of the cash flow forecast issuance decision. DeFond and Hung (2003) find cash flow forecasts are more helpful in predicting firm performance for firms with relatively: larger total accruals, more heterogeneous accounting choices compared to industry norms, higher earnings volatility, higher capital intensity (deflated by sales volume), and poorer financial health (measured by the Altman Z-score). They find that analysts are more likely to issue cash flow forecasts to aid investors in the interpretation of earnings in these cases.

We separate firm-years into above and below median partitions for each of these variables. Our results indicate that relative cash flow forecast accuracy is significantly 
associated with an analyst's career outcome in those cases in which DeFond and Hung (2003) conclude that analysts are more likely to issue a cash flow forecast. Further analysis shows that the impact of these factors on the association between accuracy and turnover is statistically significant for four of the five DeFond and Hung (2003) metrics. Results for ALTMAN_Z are not statistically significant. We interpret these crosssectional findings as brokerage firms placing increased emphasis on relative cash flow forecast accuracy in the turnover outcome when a cash flow forecast is potentially more useful to investors.

To test whether more emphasis is placed on cash flow forecast accuracy in cases in which it is a more precise signal of analyst effort or ability, we investigate the weight placed on relative cash flow forecast accuracy as the number of other analysts issuing cash flow forecasts increases. Following the economic intuition in Gibbons and Murphy (1990), we expect that relative cash flow forecasting accuracy represents a more precise estimate of analysts' effort or ability when the number of other analysts issuing cash flow forecasts increases. Thus, brokerage houses should put more weight on relative cash flow forecasting accuracy when the number of analysts issuing cash flow forecasts increases. Our findings are consistent with this prediction. We interpret this crosssectional finding as brokerage firms placing increased emphasis on relative cash flow forecast accuracy when it is more reflective of analysts' forecasting ability.

Collectively, our cross-sectional results are consistent with brokerages placing increased emphasis on the accuracy of an analyst's cash flow forecast when cash flow forecasts are useful to investors in assessing particular types of firms, and brokerages assessing the analyst relative to her peers. This paper proceeds as follows. In section 2, 
we develop our hypotheses. Section 3 describes the sample. We provide the primary empirical work in sections 4 and 5. Section 6 contains robustness checks and section 7 concludes.

\section{Hypotheses development}

Prior research (e.g., Hong and Kubik, 2003; Mikhail, Walther, and Willis, 1999) finds an inverse relation between relative earnings forecast accuracy and turnover. The verifiability of earnings forecasts and cash flow forecasts by comparison with subsequently released financial results represents an ideal opportunity for an employer to evaluate an analyst's forecasting ability. ${ }^{1}$ Furthermore, the Informativeness Principle (Holmström, 1979) indicates that evaluating analysts on both earnings and cash flow forecast accuracy is optimal if each metric provides incremental information about the analyst's effort. This discussion leads to our first hypothesis (all hypotheses stated in alternative form).

$H_{1}$ : After controlling for self-selection in an analyst's decision to issue a cash flow forecast, there will be an inverse relation between relative cash flow forecast accuracy and turnover.

Given two different metrics to evaluate analysts, we study the weight assigned to each measure. Givoly, Hayn, and Lehavy (2009) find that, relative to their annual earnings forecasts, analysts' cash flow forecasts are less accurate, more optimistically biased, and with more highly correlated forecast errors. They conclude that cash flow forecasts are of generally "low quality." These findings suggest that cash flow forecasts are less important in the turnover outcome.

$\mathrm{H}_{2}$ : After controlling for self-selection in an analyst's decision to issue a cash flow forecast, the weight placed on relative earnings forecast accuracy in the turnover outcome will be greater than the weight placed on relative cash flow forecast accuracy for analysts who issue earnings and cash flow forecasts. 
Call, Chen, and Tong (2009) document an inverse relation between relative cash flow forecast accuracy and turnover; they also find that the weight placed on relative earnings forecast accuracy is greater than the weight placed on relative cash flow forecast accuracy. They do not, however, control for self-selection in the cash flow forecast issuance decision. As discussed previously, failure to address self-selection can cause biased coefficient estimates and incorrect statistical inferences. Although $\mathrm{H}_{1}$ and $\mathrm{H}_{2}$ are neither new to the literature nor the focus of our study, we believe it is important to establish that controlling for selection does not alter the inferences of prior research. Next, we discuss our cross-sectional predictions, which are new to the literature.

DeFond and Hung (2003) document that analysts are more likely to issue cash flow forecasts in cases in which such metrics are potentially more useful in assessing firm performance: when the firm being covered has larger accruals, uses accounting methods that deviate from industry norms, has higher earnings volatility, has higher capital intensity, or is in poorer financial health. These findings are consistent with market participants demanding, and analysts responding with, cash flow forecasts for firms where such information is relatively more useful than earnings alone. Thus, we expect that the analyst's brokerage employer will place greater weight on an analyst's relative cash flow forecasting accuracy in those cases in which cash flow forecasts are more useful to investors in evaluating firm performance. This discussion leads to our third hypothesis.

$\mathrm{H}_{3}$ : In the turnover outcome, the weight placed on relative cash flow forecast accuracy will be larger in those cases in which the firm for which the cash flow forecast is issued has larger accruals, has less standard accounting method choices (relative to the industry), has higher earnings volatility, has higher capital intensity, or is in poorer financial health. 
Gibbons and Murphy (1990) note that a more precise estimate of the common or random shock (e.g., macroeconomic, industry, or firm-level shocks) to which agents are subjected is provided by relative performance measures when the agent being evaluated is compared against a larger number of other agents. In addition, relative performance evaluation (RPE) is a less effective means of evaluating agents when agents can affect the reference group to which they are compared. Gibbons and Murphy state (1990, 35-S), "Incentives to sabotage or collude with other agents subject to the same common shock are more important when the number of co-workers is small, and RPE will therefore be less effective for small groups than for large groups, ceteris paribus.” Thus, we expect that the brokerage employer will place increased weight on relative cash flow forecasting accuracy when that measure better represents the analyst's innate forecasting ability.

This discussion leads to our last hypothesis. ${ }^{2}$

\section{$H_{4}$ : In the turnover outcome, the weight placed on relative cash flow forecast accuracy will be larger when more analysts provide cash flow forecasts for the firm.}

In summary, $\mathrm{H}_{1}$ and $\mathrm{H}_{2}$ address research questions studied in Call, Chen, and Tong (2009), but after controlling for selection. $\mathrm{H}_{3}$ and $\mathrm{H}_{4}$ are new to the literature.

\section{Sample}

We address two features of our research setting that have the potential to confound our results: an environmental feature (the merger of brokerage firms) and a database feature (the coding of analyst names).

First, we control for broker mergers in our sample because Wu and Zang (2009) find that analyst career outcomes can depend on the mergers of their employers. To eliminate the effect of broker mergers on our results, we gather information on all mergers in the financial services industry satisfying the criteria identified by Wu and 
Zang (2009). ${ }^{3}$ For all broker mergers in a given year $t$ we classify an analyst as not experiencing turnover if she was employed by the target in years $\mathrm{t}-1$ or $\mathrm{t}$ and the acquirer in years $t$ or $t+1$. Thus, we assume that these changes in a particular analyst's employment are attributable to the merger of the firms involved and not the analyst's relative forecast accuracy. If our assumption is wrong, it should bias against our ability to find a relation between relative forecast accuracy and turnover.

Second, Wu and Zang (2009) also document that the I/B/E/S database contains some inconsistencies in the coding of analyst names - of most concern to us is the assignment of multiple codes to the same analyst by $\mathrm{I} / \mathrm{B} / \mathrm{E} / \mathrm{S}$. This coding could cause us to erroneously conclude that an analyst has exited the I/B/E/S database, and thus introduce error into our measure of turnover, when she has merely been assigned a new analyst code. To address this possibility, we manually cross referenced analyst names on I/B/E/S with Nelson's Directory of Investment Research for each year in our sample period. ${ }^{4}$ In our corrected sample, each analyst is associated with a unique code.

We measure both analyst-level and firm-level variables. We compute the analystlevel variables using I/B/E/S; we gather the firm-level variables from Compustat. Because we are investigating analyst turnover, measured at the analyst-year level, we aggregate all analyst and firm variables by averaging across all firms covered by an analyst in a calendar year. Our results are not sensitive to calculating medians instead.

We collect all annual earnings-per-share (EPS) forecasts issued 365 calendar days or less before the annual earnings announcement date between January 1, 1993 (the first year cash flow forecasts are included on $\mathrm{I} / \mathrm{B} / \mathrm{E} / \mathrm{S}$ ) and December 31, 2005. To be included, the forecast may not be issued by an unknown analyst. Our initial sample 
contains all analyst-firm-year observations meeting these selection criteria, where an analyst-firm-year observation may correspond to an analyst issuing one or more annual EPS forecasts for a firm, zero or more annual operating cash flow per share (CPS) forecasts for a firm, or both. In our empirical work we standardize all analyst level variables; this standardization requires that each firm be followed by at least two analysts in a given calendar year (discussed later). For each analyst-firm-year observation, we retain the last EPS and/or CPS forecast made for a firm fiscal year in the calendar year before the annual earnings announcement date recorded by $\mathrm{I} / \mathrm{B} / \mathrm{E} / \mathrm{S}$.

Our primary focus is on analysts' relative earnings and cash flow forecast accuracy for a given firm and year. We calculate analyst i's earnings (cash flow) forecast error, $\operatorname{EPSFE}_{\mathrm{i}, \mathrm{j}, \mathrm{t}}\left(\mathrm{CPSFE}_{\mathrm{i}, \mathrm{j}, \mathrm{t}}\right)$, for firm $\mathrm{j}$ in fiscal year $\mathrm{t}$ as the absolute deviation between her annual earnings (cash flow) forecast for that firm-year, $\operatorname{EPSFC}_{\mathrm{i}, \mathrm{j}, \mathrm{t}},\left(\mathrm{CPSFC}_{\mathrm{i}, \mathrm{j}, \mathrm{t}}\right)$ and the annual earnings (operating cash flow) realization reported by $\mathrm{I} / \mathrm{B} / \mathrm{E} / \mathrm{S}$ for that firm-year, $\operatorname{EPSACT}_{\mathrm{j}, \mathrm{t}}\left(\mathrm{CPSACT}_{\mathrm{j}, \mathrm{t}}\right){ }^{5}$

$\operatorname{EPSFE}_{\mathrm{i}, \mathrm{j}, \mathrm{t}}=\left|\mathrm{EPSFC}_{\mathrm{i}, \mathrm{j}, \mathrm{t}}-\mathrm{EPSACT}_{\mathrm{j}, \mathrm{t}}\right|$

$\operatorname{CPSFE}_{\mathrm{i}, \mathrm{j}, \mathrm{t}}=\left|\mathrm{CPSFC}_{\mathrm{i}, \mathrm{j}, \mathrm{t}}-\operatorname{CPSACT}_{\mathrm{j}, \mathrm{t}}\right|$

To orthogonalize the analyst and firm-level variables that we include in our empirical specifications, we rank EPSFE and CPSFE within analysts following the same firm, and convert these ranks to a relative score, following Hong, Kubik, and Solomon (2000). Because analysts follow different firms with varying levels of earnings (cash flow) predictability, we separately rank each of the above forecast error metrics relative to all other analysts following that firm in that year (hence, our requirement that each firm be followed by at least two analysts). In the case of tied analysts, we average the 
ranks corresponding to the tied observations. The analyst producing the most accurate annual earnings (cash flow) forecast for the firm earns a rank of one. In the case of no tied observations, the least accurate earnings (cash flow) forecaster receives a rank equal to the number of analysts producing earnings (cash flow) forecasts for that firm in that calendar year. We convert these ranks to a score, REL_SCORE $E_{\mathrm{i}, \mathrm{j}, \mathrm{t}}$, ranging from zero (least accurate) to 100 (most accurate):

$\mathrm{REL}_{-} \mathrm{SCORE}_{\mathrm{i}, \mathrm{j}, \mathrm{t}}=100-\left[\frac{\mathrm{RANK}_{\mathrm{i}, \mathrm{j}, \mathrm{t}}-1}{\text { \#ANALYSTS }_{\mathrm{j}, \mathrm{t}}-1}\right] \times 100$,

where RANK $_{i, j, t}$ represents the rank of analyst i's EPS or CPS forecast accuracy versus all other analysts providing an annual EPS or CPS forecast for firm $\mathrm{j}$ in year $\mathrm{t} .{ }^{6}$ This relative ranking procedure also has the advantages of reducing the effect of extreme observations and any nonlinearity in the data.

Because our interest is the relation between analyst turnover and relative earnings and cash flow forecast accuracy, we average REL_SCORE $\mathrm{i}_{\mathrm{i}, \mathrm{j}, \mathrm{t}}$ across all firms analyst $\mathrm{i}$ follows in year $t$; we call these metrics EPS_ACC $\mathrm{A}_{\mathrm{i}, \mathrm{t}}$ and CPS_ACC $\mathrm{AC}_{\mathrm{i}, \mathrm{t}}$ (we suppress variable subscripts in the remaining narrative for expositional convenience). Thus, the unit of observation of our final sample is at the analyst-year level, yielding 26,415 analyst-year observations.

We calculate additional analyst level measures used to predict whether an analyst will issue cash flow forecasts, including her: firm-specific earnings forecasting experience, EXPERIENCE; size of the brokerage house employer, BROK_SIZE; number of firms for which she provides earnings forecasts, NUM_FIRMS; the relative EPS 
forecast accuracy in the previous year, L_EPS_ACC; number of calendar days between the earnings forecast and the annual earnings announcement date in the previous year, L_EPS_HOR; and number of earnings forecasts issued for the firm in the previous year, L_EPS_FREQ. The last three variables are lagged by one year as signified by "L" in the variable name. We lag these variables to ensure that they are available before the current year so that they can be used to predict whether an analyst will issue cash flow forecasts in the current year. We define these variables in the Appendix. We rank these measures and calculate the relative scores for each variable as below (except for L_EPS_ACC which follows (1) and (3)).

$\operatorname{REL} \_S C O R E_{i, j, t}=\left[\frac{\text { RANK }_{i, j, t}-1}{\text { ANALYSTS }_{j, t}-1}\right] \times 100$

Table 1 Panel A provides the distribution of the sample. As expected, 1993, the first year for which $\mathrm{I} / \mathrm{B} / \mathrm{E} / \mathrm{S}$ began tracking cash flow forecasts, has the smallest percentage of observations (2.99\%). The top portion of Panel B contains descriptive statistics on the relative ranks associated with the analyst-level variables. These statistics are calculated by averaging the data across firms for an analyst-year; thus, the distributional measures presented pertain to the mean (using the median does not alter our results). As expected given our ranking convention, the mean (median) values of the analyst measures are close to 50, except for NUM_FIRMS. ${ }^{7}$

To aid interpretation of the tabulated ranked measures, we present the unranked (raw) analyst-level variables in the middle portion of Panel B. These data indicate that the median analyst works for a brokerage employing 42 analysts and has 1.7 years of firm-specific forecasting experience following 12 firms for each of which she provides 
approximately 3 annual earnings forecasts that precede the earnings announcement by about 140 calendar days (just under five months).

We report measures describing the sample firms in the bottom portion of Panel B. Similar to the analyst-level variables, these variables are also aggregated by averaging across all firms followed by a given analyst in a calendar year. Thus, these measures are characteristics of firms in an analyst's portfolio in a calendar year, not firm-level measures.

We report the asset-deflated absolute difference between earnings and operating cash flows, ACCRUALS; an indication of the extent to which the firm's accounting choices differ from the most frequently chosen accounting method in the firm's industry, ACCT_CHOICE; the coefficient of variation of earnings, VOLATILITY; the capital intensity of the firm's operations, CAP_INT; the Altman Z-score (Altman, 1968), a measure of financial solvency, ALTMAN_Z; and the market value of equity, SIZE. These variables, drawn from DeFond and Hung (2003), are defined in the Appendix. ${ }^{8}$ We present univariate Pearson and Spearman correlations in Table 2. We highlight the correlations between the independent variables and TURNOVER and CFC, defined as:

TURNOVER $=$ An indicator variable equal to one if the analyst is present on the $\mathrm{I} / \mathrm{B} / \mathrm{E} / \mathrm{S}$ database in the current calendar year but not present in the subsequent calendar year; ${ }^{9}$ and

$\mathrm{CFC}=\quad$ An indicator variable taking the value of one if an analyst's cash flow forecast accuracy score is nonmissing during the calendar year, zero otherwise. We interpret CFC as whether or not an analyst has issued any annual operating cash flow forecasts. ${ }^{10}$ 
The univariate correlations are generally consistent with prior work (e.g., Call, Chen, and Tong, 2009; DeFond and Hung, 2003; Ertimur and Stubben, 2006; Hong, Kubik, and Solomon, 2000; Mikhail, Walther, and Willis, 1999). We find a statistically negative correlation between EPS_ACC (CPS_ACC) and TURNOVER; relatively more accurate analysts are less likely to experience turnover in the next year. Moreover, CFC and TURNOVER are inversely related, consistent with the issuance of a cash flow forecast reducing the likelihood of turnover. Spearman correlations are similar.

Regarding the firm-level determinants of cash flow forecast issuance, we find a statistically positive association between the likelihood that a cash flow forecast is issued, CFC, and: ACCT_CHOICE, VOLATILITY, CAP_INT, and SIZE, and a negative relation between CFC and ALTMAN_Z. Spearman correlations yield similar results. We find a statistically positive (negative) Spearman (Pearson) correlation between CFC and ACCRUALS.

Regarding the analyst-level determinants of cash flow forecast issuance, we find a statistically positive association between CFC and: EXPERIENCE, BROK_SIZE, NUM_FIRMS, and L_EPS_FREQ. Thus, more experienced analysts, analysts employed with larger brokerages, analysts following more firms, and analysts providing earnings forecasts more frequently, are more likely to issue cash flow forecasts (Spearman correlations yield similar inferences except that the Spearman correlation between CFC and L_EPS_ACC is statistically positive while the Pearson correlation is positive but not statistically significant). We find a negative Pearson and Spearman correlation between CFC and L_EPS_HOR.

\section{Empirical work: analyst turnover}




\subsection{THE DETERMINANTS OF CASH FLOW FORECAST ISSUANCE}

Our interest is the association between analyst turnover and the relative accuracy of her earnings and cash flow forecasts. To calculate an analyst's relative cash flow forecast accuracy, the analyst must have issued a cash flow forecast. Because the decision to issue a cash flow forecast is a choice variable, we model the relation between turnover and cash flow forecast accuracy endogenously. We estimate the following equation, which includes firm-level (DeFond and Hung, 2003) and analyst-level (Ertimur and Stubben, 2006) determinants of the cash flow forecast issuance decision. ${ }^{11}$ Eq. (4) represents the selection equation in our two-stage simultaneous estimation procedure (Section 4.2). G is the cumulative probit distribution function. Variables are defined in the Appendix.

$$
\begin{aligned}
& \operatorname{Prob}(\mathrm{CFC}=1)=\mathrm{G}\left(\beta_{0}+\beta_{1} \mathrm{ACCRUALS}+\beta_{2} \mathrm{ACCT} \text { CHOICE }+\beta_{3}\right. \text { VOLATILITY } \\
& +\beta_{4} \mathrm{CAP} \_\mathrm{INT}+\beta_{5} \mathrm{ALTMAN} Z+\beta_{6} \mathrm{SIZE}+\beta_{7} \mathrm{EXPERIENCE}+\beta_{8} \mathrm{BROK} \_\mathrm{SIZE} \\
& \left.+\beta_{9} \mathrm{NUM} \text { _FIRMS }+\beta_{10} \mathrm{~L} \_\mathrm{EPS} \_\mathrm{ACC}+\beta_{11} \mathrm{~L} \_\mathrm{EPS} \_\mathrm{HOR}+\beta_{12} \mathrm{~L} \_ \text {EPS_FREQ }\right)
\end{aligned}
$$

Following DeFond and Hung (2003), we expect a positive relation between CFC (the issuance of a cash flow forecast) and: ACCRUALS, ACCT_CHOICE, VOLATILITY, CAP_INT, and ALTMAN_Z. Similar to DeFond and Hung (2003), we include SIZE as a control variable and make no prediction regarding its sign.

We make no prediction regarding the relation between analyst experience and CFC. On one hand, prior work (e.g., Clement, 1999; Mikhail, Walther, and Willis, 1997) suggests that more experienced analysts are more accurate earnings-per-share forecasters, yielding a positive relation. Leone and Wu's (2007) study, however, suggests that less experienced analysts may be more likely to issue cash flow forecasts to get noticed or 
because they are more talented. We expect a positive relation between brokerage firm size, BROK_SIZE, and CFC. Analysts from larger brokerages should find it less costly to issue cash flow forecasts given the resources available to them (Clement, 1999; Jacob, Lys, and Neale, 1999).

We make no sign prediction regarding the relation between the number of firms an analyst follows, NUM_FIRMS, and CFC. Analysts following more firms should have broader industry knowledge (Leone and $\mathrm{Wu}, 2007$ ) finding it less costly to provide cash flow forecasts for a firm, yielding a positive association between NUM_FIRMS and CFC. Alternatively, analysts following more firms have a heavier workload (e.g., Clement, 1999), which may make them less likely to issue cash flow forecasts, implying a negative relation between NUM_FIRMS and CFC.

Analysts who produce more accurate earnings-per-share forecasts may be more facile at the forecasting task in general—suggesting a positive relation between prior earnings-per-share forecast accuracy, L_EPS_ACC, and CFC. We make no sign prediction regarding the association between earnings-per-share forecast horizon, L_EPS_HOR, and CFC. We include this variable as a control because forecast horizon is an important determinant of earnings forecasting accuracy. Last, similar to Jacob, Lys, and Neale (1999), we use prior earnings-per-share forecasting frequency, L_EPS_FREQ, as a proxy for analyst effort. We expect that analysts who issue more earnings-per-share forecasts are, in general, harder workers; therefore, we expect a positive relation between L_EPS_FREQ and CFC. ${ }^{12}$ Sign predictions are summarized in Table 3.

In Table 3 we estimate Eq. (4) with the analyst-level variables only (column 3) and with the analyst-level and firm-level variables together (column 4). We discuss the 
column 4 estimation results. Like DeFond and Hung (DH, 2003), we find a positive (negative) relation between ACCT_CHOICE, VOLATILITY, CAP_INT, and SIZE (ALTMAN_Z) and an analyst's decision to issue a cash flow forecast. The only difference between our results and DH is that we find a negative, and marginally significant, relation between ACCRUALS and cash flow forecast issuance; DH find a statistically positive association. We examine this discrepancy in section 6.3.

Consistent with our predictions and with Ertimur and Stubben (2006), we find a positive relation between BROK_SIZE and L_EPS_FREQ and cash flow forecast issuance. We find a positive (negative) relation between NUM_FIRMS (L_EPS_HOR) and cash flow forecast issuance. Ertimur and Stubben's (2006) coefficient estimates for these variables agree in sign with our findings, but their coefficient estimates are not statistically significant. Hence, analysts from larger brokerages who follow more firms, forecast closer to the annual earnings announcement date, and revise their earnings forecasts more frequently are more likely to issue cash flow forecasts. The remaining analyst-level variables are not statistically significant.

\subsection{RELATION BETWEEN RELATIVE CASH FLOW AND RELATIVE EARNINGS FORECAST ACCURACY AND TURNOVER}

The decision to issue a cash flow forecast is a choice variable. We model the relation between turnover and cash flow forecast accuracy endogenously. In the first stage, we model the cash flow forecast issuance decision using Eq. (4). In the second stage, we model the relation between analyst turnover and relative earnings and cash flow forecast accuracy; the dependent variable, TURNOVER, is an indicator taking the value of one if the analyst is present on the $\mathrm{I} / \mathrm{B} / \mathrm{E} / \mathrm{S}$ database in a given calendar year, but absent the next year (zero otherwise): 
$\operatorname{Prob}($ TURNOVER $=1)=\mathrm{F}\left(\varphi_{0} \mathrm{CFC}+\varphi_{1} \times\left(\mathrm{CFC} \times \mathrm{EPS} \_\mathrm{ACC}\right)\right.$

$\left.+\varphi_{2} \times\left(\mathrm{CFC} \times \mathrm{CPS} \_\mathrm{ACC}\right)+\varphi_{3} \times(1-\mathrm{CFC})+\varphi_{4} \times\left((1-\mathrm{CFC}) \times \mathrm{EPS} \_\mathrm{ACC}\right)\right)$

F is the cumulative probit distribution function. EPS_ACC and CPS_ACC, relative EPS and CPS forecast accuracy, respectively, are defined in the Appendix. We include current year measures of relative EPS and CPS forecast accuracy because an analyst's relative forecast accuracy in year $\mathrm{t}$ may affect her probability of turnover in year $\mathrm{t}+1 .{ }^{13}$

Because an analyst's cash flow forecast accuracy (CPS_ACC) is a function of her decision to issue a cash flow forecast (CFC) we expect that the disturbance terms in Eqs. (4) and (5) will be correlated due to this self-selection. We address this correlation by estimating Eqs. (4) and (5) simultaneously. Failure to control for across equation correlated disturbance terms would yield biased coefficient estimates. Because the dependent variables in Eqs. (4) and (5) are binary, we estimate the system as a seemingly unrelated bivariate probit model. This approach allows for across equation correlation in the disturbance terms arising from self-selection in the decision to issue a cash flow forecast. To aid interpretation of the coefficient estimates, we tabulate the coefficient marginal effects and include discussion of the economic significance of the results.

The specification of Eq. (5) has the advantage in allowing separate estimation for those analysts who issue earnings and cash flow forecasts and those who issue earnings forecasts only. For analysts who issue earnings and cash flow forecasts $(\mathrm{CFC}=1)$, Eq. (5) becomes:

$\operatorname{Prob}($ TURNOVER $=1)=\mathrm{F}\left(\varphi_{0}+\varphi_{1}\right.$ EPS_ACC $+\varphi_{2}$ CPS_ACC $)$

Thus, turnover depends on both relative EPS and CPS forecast accuracy. The coefficients of EPS_ACC and CPS_ACC capture the differential weightings on relative 
earnings and cash flow forecast accuracy for those analysts issuing both types of forecasts. If relative earnings and cash flow forecasting accuracy decrease the likelihood of an analyst experiencing turnover in the subsequent year, then we predict that the coefficient estimates of $\varphi_{1}$ and $\varphi_{2}$ will be negative. If $\varphi_{1}-\varphi_{2}<0$, as predicted in $\mathrm{H}_{2}$, then relative earnings forecast accuracy weights more heavily than relative cash flow forecast accuracy in reducing the probability of turnover for analysts issuing both types of forecasts.

For analysts who issue earnings forecasts only $(\mathrm{CFC}=0)$, Eq. (5) becomes: $\operatorname{Prob}($ TURNOVER $=1)=\mathrm{F}\left(\varphi_{3}+\varphi_{4}\right.$ EPS_ACC $)$

Hence, turnover depends only on relative earnings forecast accuracy. We expect $\varphi_{4}$ to be negative.

Our predictions are summarized in Table 4 Panels A and B, which contains the results of estimating Eqs. (4) and (5) as a seemingly unrelated bivariate probit system. The correlation between the disturbance terms is 0.16 (two-tailed $p<0.01$ ), suggesting that there is across equation correlation in the error terms and that the use of seemingly unrelated regression techniques is appropriate. As reported in Table 4 Panel A, the first stage estimation yields identical inferences to those in Table 3.

Regarding the second stage estimation results, we find that analysts who issue cash flow forecasts and who are relatively more accurate earnings forecasters are less likely to experience turnover; the coefficient estimate associated with $\mathrm{CFC} \times \mathrm{EPS} \_\mathrm{ACC}$ is -0.0314 (two-tailed $p<0.01$ ). This finding for relative earnings forecasting extends to analysts who do not issue cash flow forecasts; the coefficient estimate associated with 
$(1-$ CFC $) \times$ EPS_ACC is -0.0296 (two-tailed $\mathrm{p}<0.01) .{ }^{14}$ Consistent with $\mathrm{H}_{1}$, we find that relatively more accurate cash flow forecasts reduce the likelihood of turnover (coefficient estimate for CFC $\times$ CPS_ACC $=-0.0023$, two-tailed $\mathrm{p}<0.05$ ). The marginal effects associated with the relative earnings and cash flow coefficient estimates, for analysts who issue both EPS and CPS forecasts, are -0.0009 and -0.0001 , respectively (two-tailed $\mathrm{p}<0.01$ and $\mathrm{p}<0.05$, respectively). The pseudo- $\mathrm{R}^{2}$ measure for Eq. (5) is $14.3 \%$.

To interpret the economic significance of these results we note that the unconditional probability of turnover in any given year in our sample is $28.17 \%$, comparable to $25.78 \%$ documented by Call, Chen, and Tong (2009). Because our relative accuracy measures are ranked from 0 to 100 , we calculate the change in the probability of turnover for an analyst moving from the first to third quartile in relative ranking by multiplying the estimated marginal effects by 50 . Hence, the reduction in the probability of turnover for an analyst who issues a cash flow forecast and moves from the first to the third quartile in relative EPS (CPS) accuracy is $0.0009 \times 50=4.5 \%(0.0001 \times$ $50=.5 \%)$. These amounts account for approximately $16 \%(0.045 \div 0.2817)$ and $1.8 \%$ $(0.005 \div .2817)$, respectively, of the unconditional probability that an analyst experiences turnover in a given year. Thus, our findings indicate that the effect of relative CPS accuracy on turnover is smaller than that of relative EPS accuracy.

As indicated in Table 4 Panel B, the coefficient estimate associated with EPS_ACC $\left(\varphi_{1}\right)$ in Eq. $(5 a)$ is -0.0314 (two-tailed $\left.p<0.01\right)$. The coefficient estimate associated with CPS_ACC $\left(\varphi_{2}\right)$ in Eq. $(5 \mathrm{a})$ is -0.0023 (two-tailed $\left.\mathrm{p}<0.05\right)$ and $\varphi_{1}-\varphi_{2}=$ $-0.0314--0.0023<0\left(\chi^{2}(1)=12.81\right.$, two-tailed $\left.\mathrm{p}<0.01\right)$. Hence, consistent with $\mathrm{H}_{2}$, 
we find, for analysts issuing both EPS and CPS forecasts, relative earnings forecasting accuracy is more important to an analyst's career outcome than is her relative cash flow forecasting ability. Although we have no ex-ante hypothesis, we compare, and find that, $\varphi_{3}-\varphi_{0}$ is statistically positive (two-tailed $\mathrm{p}<0.01$ ). Therefore, not issuing a cash flow forecast increases the likelihood of turnover.

We conclude the following. First, both relative earnings forecast accuracy and relative cash flow forecast accuracy are inversely related with security analyst turnover. Second, the marginal effect of relative cash flow accuracy on turnover is significantly less than that associated with relative earnings forecast accuracy. Last, not issuing a cash flow forecast increases the likelihood that an analyst experiences turnover. These results are consistent with prior empirical research on the association between analyst turnover and relative earnings and cash flow forecast accuracy (e.g., Call, Chen, and Tong, 2009; Hong, Kubik, and Solomon, 2000; Mikhail, Walther, and Willis, 1999). Next, we investigate cross-sectional variation in an analyst's career outcome and the weight placed on relative cash flow forecast accuracy.

\section{Empirical work: cross-sectional analyses}

\subsection{CROSS-SECTIONAL VARIATION IN THE WEIGHT PLACED ON RELATIVE CASH FLOW FORECAST ACCURACY AND TURNOVER CONDITIONAL ON THE USEFULNESS OF CASH FLOW FORECASTS}

Our findings indicate that both relative earnings and cash flow forecast accuracy are important to an analyst's career outcome, with earnings forecast accuracy being more heavily weighted in the turnover specification. DeFond and Hung (2003) indicate that cash flow forecast issuance is more likely when accruals are larger, accounting choices deviate more from the industry norm, earnings are more volatile, capital intensity is 
higher, or Altman's Z is lower. This increased likelihood of cash flow forecast issuance is consistent with cash flow forecasts being more useful to investors in those settings.

Thus, we expect that relative cash flow forecast accuracy should matter more to an analyst's career outcome when cash flow forecast accuracy should matter more to investors. Hence, more weight will be placed on relative cash flow forecast accuracy in evaluating an analyst when accruals are larger, accounting choices deviate more from the industry norm, earnings are more volatile, capital intensity is higher, or Altman's Z is lower. (Because firm size is a control variable with no ex ante sign prediction, we exclude it.)

To capture this potential cross-sectional variation, we conduct two complementary analyses. In the first analysis, we provide univariate evidence on the association between relative cash flow forecasting accuracy and turnover. We split the sample into above the median (cash flow forecasts more useful) and below the median (cash flow forecasts less useful) partitions for each of ACCRUALS, ACCT_CHOICE, VOLATILITY, CAP_INT, and ALTMAN_Z. Thus, we have five separate partitions of the sample. We reestimate Eqs. (4) and (5) as a system separately for each of these five sample partitions. ${ }^{15}$ We use the firm-level variables examined in DeFond and Hung (2003) to partition the sample because they identify those metrics as affecting investors' ability to gauge firm performance. Because the link between the analyst-level variables we investigate and investors' assessment of firm performance is less clear, we do not partition the sample using the analyst-level variables. We present the coefficient estimates associated with CFC $\times$ CPS_ACC for each partition. We test for differences in the coefficient estimates between the two sub samples. 
Table 5 Panel A contains the estimation summary. ${ }^{16}$ We find that the coefficient estimates associated with $\mathrm{CFC} \times \mathrm{CPS} \_\mathrm{ACC}$ are statistically negative for all five variables in the above median partition (two-tailed $\mathrm{p}<0.10$ in all cases with the statistical significance greater for four of the coefficient estimates). These occurrences correspond to instances in which DeFond and Hung (2003) conclude that analysts are more likely to issue cash flow forecasts to aid in the interpretation of earnings and the assessment of firm prospects. The coefficient estimates in the below median partition are not statistically different from zero. We note, however, that the difference in the effect of relative cash flow forecast accuracy on the likelihood of turnover between the above and below median partitions is statistically significant only for ACCRUALS, ACCT_CHOICE, and VOLATILITY. We view these univariate comparisons as generally consistent with $\mathrm{H}_{3}$.

As a multivariate test of $\mathrm{H}_{3}$, in the second analysis, we reestimate Eqs. (4) and (5) as a system after including all five DeFond and Hung (2003) variables in Eq. (5) simultaneously. We create five indicator variables, $\mathrm{ABOVE}^{\mathrm{I}}$, equal to one (zero) when the variable of interest is above (below) its sample median where $\mathrm{I}=\{$ ACCRUALS, ACCT_CHOICE, VOLATILITY, CAP_INT, or ALTMAN_Z\}. We include ABOVE ${ }^{\mathrm{I}}$ as a three-way interaction term, $\mathrm{ABOVE} \mathrm{I}^{\mathrm{I}} \times \mathrm{CFC} \times \mathrm{CPS} \_\mathrm{ACC}$, for all five variables simultaneously. Hence, five three-way interaction terms are included in Eq. (5) and $\mathrm{ABOVE}^{\mathrm{I}}$ enters the estimation as a zero-one indicator variable. Again, because our focus is on the interaction between relative cash flow forecast accuracy when the variables we examine are hypothesized to be of most use to investors in assessing firm performance, for brevity we tabulate only the three-way interaction terms. 
Table 5 Panel B contains the estimation summary. The results are generally consistent with our predictions in $\mathrm{H}_{3}$. The model pseudo- $\mathrm{R}^{2}$ measure is $14.8 \%$. The coefficient estimates associated with $\mathrm{ABOVE}{ }^{\mathrm{I}} \times \mathrm{CFC} \times \mathrm{CPS} \_\mathrm{ACC}$ are statistically negative for ACCRUALS, ACCT_CHOICE, VOLATILITY, and CAP_INT (two-tailed p $<0.05$ in all cases). The exception is for ALTMAN_Z for which the interaction term is negative, but not statistically significant. We gauge the economic significance of the marginal effects using the same approach in Table 4 Panel B. We find economic effects of $7.1 \%, 3.5 \%, 1.8 \%$, and $1.8 \%$ for ACCRUALS, ACCT_CHOICE, VOLATILTY, and CAP_INT, respectively. (We do not present the economic significance for ALTMAN_Z because it is not statistically different from zero.)

The $7.1 \%$ effect is calculated as $(0.0004 \times 50) \div 0.2817=0.0710$. 0.0004 is the marginal effect, 50 is used to measure the effect of moving from the first to the third quartile, and 0.2817 is the unconditional probability that an analyst experiences turnover in our sample (other effects calculated similarly). We interpret the $7.1 \%$ estimate as follows. Compared with Analyst X who follows a firm with smaller accruals (below the median), for Analyst $\mathrm{Y}$ who follows a firm with larger accruals (above the median), the reduction in the probability of turnover associated with an improvement in relative cash flow forecast accuracy from the first to the third quartile is greater by $7.1 \%$ of the $28.17 \%$ unconditional probability of turnover.

Overall, we interpret the Table 5 findings as generally consistent with $\mathrm{H}_{3}$. Specifically, relative cash flow forecast accuracy is associated with turnover in those instances in which cash flow forecasts are more useful indicators of firm performance 
(Table 5 Panel A). Moreover, this conclusion holds after including all five firm-level variables in the model simultaneously (Table 5 Panel B).

\subsection{CROSS-SECTIONAL VARIATION IN THE WEIGHT PLACED ON RELATIVE CASH FLOW FORECAST ACCURACY AND TURNOVER CONDITIONAL ON ANALYST FOLLOWING}

As indicated in $\mathrm{H}_{4}$, we expect the reduction in the probability of turnover to be larger for relatively more accurate cash flow forecasters when the number of other analysts providing cash flow forecasts for the firm is greater. \#AN_CPS is defined as the number of analysts providing at least one annual CPS forecast for the firm in the current calendar year (averaged across all firms for which the analyst issues one or more earnings or cash flow forecasts in the current calendar year). We reestimate Eqs. (4) and (5) as a system, but after modifying Eq. (5) to include information on \#AN_CPS.

If, as the intuition in Gibbons and Murphy (1990) suggests, more weight is placed on relative cash flow forecast accuracy when the number of analysts providing cash flow forecasts is larger, then we expect \#AN_CPS $\times$ CFC $\times$ CPS_ACC to be statistically negative. This finding would indicate that relative cash flow forecasting accuracy has a greater impact on reducing turnover when the number of analysts issuing cash flow forecasts for the firm is larger.

Table 6 contains the estimation results. For brevity, we tabulate the second stage (Eq. (5)) estimation; the tabulated pseudo- $\mathrm{R}^{2}$ measure (14.4\%) is comparable to Eq. (5) in Table 4. Consistent with our expectation and $\mathrm{H}_{4}$, the coefficient estimate associated with \#AN_CPS $\times$ CFC $\times$ CPS_ACC is -0.0006 and statistically significant (two-tailed $p<$ 0.01). We conclude that relative cash flow forecasting accuracy reduces the probability of turnover more when the number of analysts providing CPS forecasts is larger. 
We investigate whether the sample partitions used in testing $\mathrm{H}_{3}$ (e.g., above median partitions of ACCRUALS, etc.) are driving the results for $\mathrm{H}_{4}$ (e.g., \#AN_CPS is large). DeFond and Hung (2003) show that analysts are more likely to issue cash flow forecasts for firms with the characteristics identified in $\mathrm{H}_{3} . \mathrm{H}_{4}$ investigates whether cash flow forecast accuracy is more important when more analysts provide cash flow forecasts for the firm. Hence, we wish to provide assurance that $\mathrm{H}_{4}$ is not an artifact of more analysts providing cash flow forecasts in cases in which such forecasts are more useful firm-level performance measures. $\mathrm{H}_{3}\left(\mathrm{H}_{4}\right)$ is designed to examine whether relative cash flow forecast accuracy is weighted more heavily in the turnover outcome when cash flow forecasts are more useful firm-level (analyst-level) performance measures.

We reestimate the Table 6 empirical model for ten separate sub samples (the Table 6 model estimated for the sample partition of analyst-firm-year observations for which ACCRUALS was above the sample median, the Table 6 model estimated for the sample partition of analyst-firm-year observations for which ACCRUALS was below the sample median, etc.). The coefficient estimate associated with \#AN_CPS $\times$ CFC $\times$ CPS_ACC is statistically negative in both the above and below sample partitions for each of the DeFond and Hung (2003) variables (two-tailed $p<0.05$ or greater in all cases). We conclude that the economic phenomena underlying the predictions in $\mathrm{H}_{3}$ and $\mathrm{H}_{4}$ are distinct.

\section{Robustness}

\subsection{PROMOTIONS AND DEMOTIONS}

We assume that analysts are averse to turnover. Some changes of employer may be voluntary and represent favorable career outcomes ("promotions"); other changes may 
be involuntary and represent unfavorable career outcomes ("demotions"). To assess the sensitivity of our findings to promotions and demotions, we reestimate Eqs. (4) and (5) jointly, replacing TURNOVER with PROMOTE and DEMOTE. Following Hong, Kubik, and Solomon (2000) we define PROMOTE (DEMOTE) as an indicator variable equal to one when an analyst remains on the I/B/E/S database from year $t$ to $t+1$ but moves to a brokerage house employing more (fewer) than 25 analysts, zero otherwise. We assume that larger (smaller) brokerage houses are more (less) prestigious and moves to such houses represent promotions (demotions).

Our findings are summarized next. For analyst promotions (i.e., PROMOTE =1) we find that relatively better cash flow forecast accuracy increases the probability of moving to a larger brokerage house in the next year. This finding is consistent with Hong and Kubik (2003) who find that relatively more accurate (earnings) forecasters are more likely to be promoted. For analyst demotions (i.e., DEMOTE $=1$ ), however, unlike Hong and Kubik (2003), we do not find a relation between relative cash flow forecast accuracy and the likelihood of demotion.

\subsection{INCLUSION OF BROKER EFFECTS}

Brokerage houses may differ in their policies regarding the issuance of cash flow forecasts and analyst turnover. We reestimate Eqs. (4) and (5) as a bivariate probit system after including broker effects in each equation. To construct these broker effects, for each brokerage house, $B_{1}, B_{2}, B_{3}, \ldots$ in our sample we create indicator variables $\mathrm{B}_{1}$ Effect, $\mathrm{B}_{2}$ Effect, $\mathrm{B}_{3}$ Effect, ... equal to one (zero) if the analyst is employed by brokerage house $\mathrm{B}_{1}, \mathrm{~B}_{2}, \mathrm{~B}_{3}, \ldots$ respectively. Because there are 571 brokerage houses in 
our sample we have 570 broker effect indicator variables. We include these 570 broker effect indicator variables simultaneously in Eqs. (4) and (5).

All our inferences are unchanged. The coefficient estimate associated with CFC $\times$ EPS_ACC is -0.0315 ; the coefficient estimate associated with CFC $\times$ CPS_ACC is -0.0029 (two-tailed $\mathrm{p}<0.01$ in both cases). The magnitudes of these coefficient estimates are quite similar to what we report in Table 4 . We conclude that our results are not attributable to potential differences across brokerage houses in policies regarding cash flow forecast issuance and/or analyst turnover.

\subsection{EXAMINATION OF INCONSISTENT SIGN ON ACCRUALS}

We replicate DeFond and Hung (DH, 2003) at the analyst-year level by estimating the following model using maximum likelihood estimation techniques:

$\operatorname{Prob}(\mathrm{CFC}=1)=\mathrm{G}\left(\beta_{0}+\beta_{1} \mathrm{ACCRUALS}+\beta_{2}\right.$ ACCT_CHOICE $+\beta_{3}$ VOLATILITY

$+\beta_{4} \mathrm{CAP} \_$INT $+\beta_{5}$ ALTMAN_Z $+\beta_{6}$ SIZE)

We find a negative, rather than positive, coefficient estimate associated with ACCRUALS. We believe this discrepancy could be attributable to differences in the sample periods examined, extreme observations (as illustrated in Table 2, the Pearson/Spearman correlations between ACCRUALS and CFC are of opposite signs), or the data aggregation used to construct our variables. To investigate the sensitivity of this finding to the sample period examined, unreported results show that estimating Eq. (6) annually yields, consistent with DeFond and Hung (DH, 2003), a positive coefficient estimate for ACCRUALS in five of the seven years during 1993-1999 (DH's sample period). Estimating Eq. (6) annually during 1993-2005 (our sample period) ACCRUALS has a positive coefficient estimate in seven of the thirteen years examined (2000 and 2002 are the only years during $2000-2005$ with a positive coefficient estimate). Thus, it is 
possible that differences in the sample periods examined may affect the sign associated with ACCRUALS.

\section{Conclusion}

Controlling for self-selection in the cash flow forecast issuance decision, we investigate the relation between security analyst turnover and the relative accuracy of their earnings and cash flow forecasts. Consistent with Call, Chen, and Tong (2009), we find the following. First, relatively more accurate earnings and cash flow forecasts reduce the probability of an analyst experiencing turnover in the subsequent year. Second, relative earnings forecast accuracy is more strongly associated with turnover than is relative cash flow forecast accuracy.

New to the literature, we find that relative cash flow forecast accuracy is more heavily weighted in the turnover outcome in cases in which cash flow forecasts are more informative about future firm performance. We also find that relative cash flow forecast accuracy reduces turnover more when this metric better assesses an analyst's forecasting ability. We do not study other attributes of the cash flow forecast. Future research might address whether brokerage firms consider the order in which an analyst issues her forecasts, which may give the analyst a timing advantage. Moreover, an investigation for why ACCRUALS may increase or decrease the likelihood of cash flow forecast issuance depending on the year examined also represents a potentially interesting avenue for future research. 


\section{References}

Altman, E. (1968). Financial Ratios, Discriminant Analysis, and the Prediction of Corporate Bankruptcy. The Journal of Finance, 23, 589-609.

Asquith, P., Mikhail, M. \& Au, A. (2005). Information Content of Equity Analyst Reports. Journal of Financial Economics, 75, 245-282.

Bradshaw, M. \& Brown, L. (2006). Do Sell-Side Analysts Exhibit Differential Target Price Forecasting Ability? Working paper. Boston College and Georgia State University. Available on the Social Science Research Network http://www.ssrn.com.

Brav, A. \& Lehavy, R. (2003). An Empirical Analysis of Analysts' Target Prices: Short-term Informativeness and Long-term Dynamics. The Journal of Finance, 58, 1933-1967.

Call, A., Chen, S. \& Tong, Y. (2009). Are Analysts' Earnings Forecasts More Accurate When Accompanied by Cash Flow Forecasts? Review of Accounting Studies, 14, 358391.

Clement, M. (1999). Analyst Forecast Accuracy: Do Ability, Resources, and Portfolio Complexity Matter? Journal of Accounting and Economics, 27, 285-303.

DeFond, M. \& Hung, M. (2003). An Empirical Analysis of Analysts' Cash Flow Forecasts. Journal of Accounting and Economics, 35, 73-100.

Ertimur, Y. \& Stubben, S. (2006). Analysts' Incentives to Issue Revenue and Cash Flow Forecasts. Working paper. Duke University and University of North Carolina at Chapel Hill.

Fama, E. \& French, K. (1997). Industry Costs of Equity. Journal of Financial Economics, 43, 153-193.

Francis, J. (1997). Discussion of Self-Selection and Analyst Coverage. Journal of Accounting Research, 35, 201-208.

Gibbons, R. \& Murphy, K. (1990). Relative Performance Evaluation for Chief Executive Officers. Industrial and Labor Relations Review, 43, 30S-51S.

Givoly, D., Hayn, C. \& Lehavy, R. (2009). The Quality of Analysts' Cash Flow Forecasts. The Accounting Review, 84, 1877-1911.

Greene, W. (2005). Econometric Analysis, Upper Saddle River, NJ., Prentice Hall.

Holmström, B. (1979). Moral Hazard and Observability. Bell Journal of Economics, 10, 74-91. 
Hong, H., Kubik, J. \& Solomon, A. (2000). Security Analysts' Career Concerns and Herding of Earnings Forecasts. RAND Journal of Economics, 31, 121-144.

Hong, H. \& Kubik, J. (2003). Analyzing the Analysts: Career Concerns and Biased Earnings Forecasts. The Journal of Finance, 58, 313-351.

Jacob, J., Lys, T. \& Neale, M. (1999). Expertise in Forecasting Performance of Security Analysts. Journal of Accounting and Economics, 28, 51-82.

Leone, A. \& Wu, J. (2007). What Does It Take to Become a Superstar? Evidence from Institutional Investor Rankings of Financial Analysts. Working paper. University of Miami and University of Rochester. Available on the Social Science Research Network http://www.ssrn.com.

Ljungqvist, A., Malloy, C. \& Marston, F. (2009). Rewriting History. The Journal of Finance, 64, 1935-1960.

Mikhail, M., Walther, B. \& Willis, R. (1997). Do Security Analysts Improve Their Performance with Experience? Journal of Accounting Research, 35, 131-157.

Mikhail, M., Walther, B. \& Willis, R. (1999). Does Forecast Accuracy Matter to Security Analysts? The Accounting Review, 74, 185-200.

Wu, J. \& Zang, A. (2009). What Determines Financial Analysts' Career Outcomes During Mergers? Journal of Accounting and Economics, 47, 59-86. 
TABLE 1: DESCRIPTIVE STATISTICS

\begin{tabular}{lrr}
\multicolumn{3}{l}{ Panel A: Sample distribution by year } \\
\hline Year & \# Observations & Percent \\
\hline 1993 & 791 & $2.99 \%$ \\
1994 & 1,461 & $5.53 \%$ \\
1995 & 1,652 & $6.25 \%$ \\
1996 & 1,782 & $6.75 \%$ \\
1997 & 2,027 & $7.67 \%$ \\
1998 & 2,270 & $8.59 \%$ \\
1999 & 2,435 & $9.22 \%$ \\
2000 & 2,470 & $9.35 \%$ \\
2001 & 2,397 & $9.07 \%$ \\
2002 & 2,237 & $8.47 \%$ \\
2003 & 2,219 & $8.40 \%$ \\
2004 & 2,278 & $8.62 \%$ \\
2005 & 2,396 & $9.07 \%$ \\
Total & 26,415 & $100.00 \%$ \\
& &
\end{tabular}

Panel B: Descriptive statistics $(\mathrm{N}=\mathbf{2 6 , 4 1 5})$

\begin{tabular}{|c|c|c|c|c|c|}
\hline Variable & Mean & $25^{\text {th }}$ P'tile & Median & $75^{\text {th }}$ P'tile & Std. Dev. \\
\hline \multicolumn{6}{|c|}{ Analyst-year variables (measured on ranked basis, using Eq. (3) or Eq. (3')) } \\
\hline EPS_ACC & 47.98 & 39.17 & 50.00 & 58.61 & 17.64 \\
\hline CPS $\mathrm{ACC}$ & 48.92 & 33.33 & 50.00 & 64.29 & 27.01 \\
\hline EXPERIENCE & 51.38 & 35.83 & 51.17 & 66.55 & 20.85 \\
\hline BROK_SIZE & 48.81 & 23.92 & 48.27 & 73.51 & 29.33 \\
\hline NUM F FIRMS & 38.22 & 13.18 & 33.95 & 60.68 & 28.65 \\
\hline L_EPS_ACC & 51.92 & 43.43 & 52.57 & 61.23 & 16.91 \\
\hline L_EPS_HOR & 45.77 & 35.05 & 45.85 & 56.30 & 19.07 \\
\hline L_EPS_FREQ & 48.14 & 35.14 & 50.10 & 61.94 & 20.29 \\
\hline \multicolumn{6}{|c|}{ Analyst-year variables (measured on unranked basis) } \\
\hline EPS_ACC & 0.7829 & 0.1253 & 0.2111 & 0.3718 & 12.9689 \\
\hline CPS_ACC & 4.0215 & 0.2100 & 0.4098 & 0.8151 & 113.1159 \\
\hline EXPERIENCE & 2.3157 & 0.9000 & 1.6667 & 3.0667 & 2.0923 \\
\hline BROK_SIZE & 61.2335 & 18.7778 & 42.0000 & 91.0000 & 55.9111 \\
\hline NUM_FIRMS & 13.5336 & 8.0000 & 12.0000 & 17.0000 & 9.3736 \\
\hline L_EPS_ACC & 0.6350 & 0.0535 & 0.1050 & 0.2111 & 10.1407 \\
\hline $\mathrm{L}_{-}^{-} \mathrm{EPS}^{-} \mathrm{HOR}$ & 147.6318 & 109.5000 & 139.8636 & 171.7778 & 60.0999 \\
\hline L_EPS_FREQ & 3.0237 & 2.0000 & 2.9545 & 3.7500 & 1.3620 \\
\hline \multicolumn{6}{|c|}{ Firm-year variables (measured on unranked basis) } \\
\hline ACCRUALS & 0.1083 & 0.0609 & 0.0854 & 0.1262 & 0.0923 \\
\hline ACCT_CHOICE & 0.1752 & 0.1000 & 0.1731 & 0.2500 & 0.1069 \\
\hline VOLATTILITY & 2.8738 & 1.0268 & 1.8392 & 3.3102 & 3.5720 \\
\hline CAP_INT & 1.2704 & 0.3801 & 0.6192 & 1.4601 & 1.6520 \\
\hline ALTMAN_Z & 6.0963 & 2.8272 & 4.7080 & 7.4952 & 5.3147 \\
\hline SIZE & 7.2179 & 6.3291 & 7.2056 & 8.0683 & 1.3042 \\
\hline
\end{tabular}




\section{Notes to Table 1:}

This table contains descriptive statistics on the sample ( $\mathrm{N}=26,415$ for all variables except CPS_ACC). Data presented are averaged across firms for an analyst-year observation to maintain consistency with their inclusion in our multivariate specifications. Panel A summarizes the sample distribution by year. Panel B presents the mean, median, $25^{\text {th }}$ percentile, $75^{\text {th }}$ percentile, and standard deviation for the variables. Analyst-level and firm-level variables are calculated by averaging the analyst-firm-year observations across all firms followed by an analyst in the current calendar year. Analyst-level variables are measured on a relative basis using Eq. (3) or Eq. (3'). Firm-level variables are measured on a raw or logarithmic basis. An analyst follows a firm if she issues at least one annual earnings-per-share forecast for the firm in the current calendar year. Analyst-level variable definitions follow. EPS_ACC = relative annual earnings per share forecast accuracy calculated using Eqs. (1) and (3); CPS_ACC = relative annual operating cash flow per share forecast accuracy, calculated using Eqs. (2) and (3). Higher scores for either measure denote more accurate forecasts. CPS_ACC is averaged across all firms for which the analyst issues one or more cash flow forecasts in the current calendar year. CPS_ACC is tabulated only for non-missing observations $(\mathrm{N}=5,690)$; EXPERIENCE = number of years the analyst has issued an EPS forecast for the firm, measured beginning in 1978; BROK_SIZE = number of analysts employed by the same broker as of the beginning of the calendar year; NUM_FIRMS = number of firms for which the analyst issues EPS forecasts in the current calendar year; L_EPS_ACC $=$ EPS_ACC, in the previous year; L_EPS_HOR $=$ number of calendar days between the latest EPS forecast made by the analyst in the fiscal year for the firm and the annual earnings announcement date obtained from $\mathrm{I} / \mathrm{B} / \mathrm{E} / \mathrm{S}$. This measure is calculated for the previous year; L_EPS_FREQ = number of times the analyst issued an EPS forecast for the firm in the previous calendar year. Firm-level variable definitions follow; these variables are measured at the beginning of the fiscal year; Compustat annual data item numbers are in parentheses. ACCRUALS = absolute value of net income before extraordinary items (data item \#18) less operating cash flows (data item \#308) deflated by total assets (data item \#6). For missing numerator values we estimate accruals as the asset-deflated value of the change in working capital, less depreciation (data item \#14); working capital = current assets (data item \#4) - cash (data item \#1) - current liabilities (data item \#5) + debt in current liabilities (data item \# 34); ACCT_CHOICE = index ranging from 0 to 1, computed by assigning a value of one for each firm's accounting choice that differs from the most prevalent method in the firm's industry group (Fama and French, 1997). Accounting choices are: (i) inventory valuation; (ii) investment tax credit; (iii) depreciation; (iv) successful-efforts versus full-cost for firms in extraction industries; and (v) purchase versus pooling. We calculate the score by summing the zero-one indicators and deflating by the number of accounting choices in the industry (after 2002 we ignore the purchase/pooling distinction); VOLATILITY = coefficient of variation of earnings for the firm, measured over the sample period (1993-2005) and calculated as the standard deviation of net income before extraordinary items deflated by the absolute value of the mean value of earnings during the sample period; CAP_INT = ratio of Gross Property, Plant, and Equipment (data item \#7) for the firm deflated by net sales revenue (data item \#12); ALTMAN_Z= Altman Z-score (Altman, 1968), Z $=1.2 \times(($ Current assets - current liabilities)/Total Assets $)+1.4 \times$ $(($ Retained earnings (Compustat annual data item \#36))/Total assets $)+3.3 \times($ Earnings before interest and taxes/Total assets) $+0.6 \times$ (Market value of equity/Book value of liabilities) $+1.0 \times($ Sales/Total assets) . Lower Z-scores represent poorer financial health; SIZE = natural logarithm of the market value of equity for the firm (data item $\# 25 \times$ data item \#199). 
TABLE 2: CORRELATIONS

\begin{tabular}{|c|c|c|c|c|c|c|c|c|c|c|c|c|c|c|c|c|}
\hline & 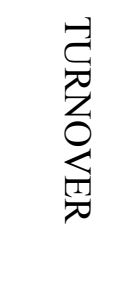 & ÂA & $\begin{array}{l}\vec{T} \\
\vec{\Omega} \\
\stackrel{\Omega}{\Omega} \\
\Omega\end{array}$ & $\begin{array}{l}\Omega \\
\stackrel{\Omega}{\Omega} \\
\stackrel{\Omega}{\Omega}\end{array}$ & 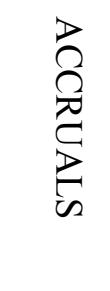 & 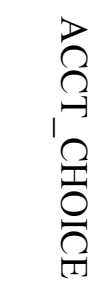 & 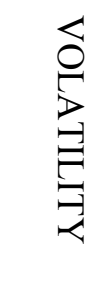 & 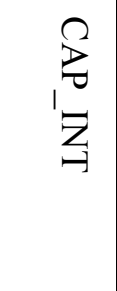 & 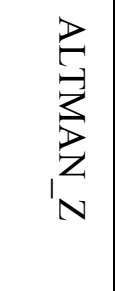 & $\stackrel{\Omega}{N}$ & 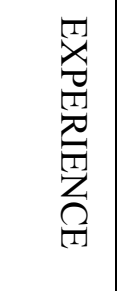 & 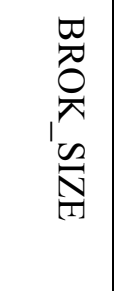 & 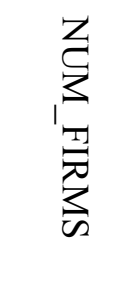 & 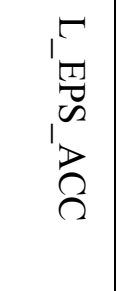 & 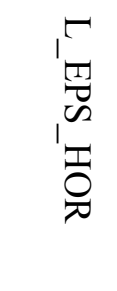 & 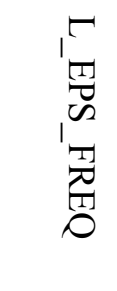 \\
\hline TURNOVER & & -0.06 & -0.36 & -0.09 & 0.04 & -0.03 & -0.01 & 0.01 & 0.01 & 0.02 & 0.03 & -0.04 & -0.28 & -0.03 & 0.02 & -0.07 \\
\hline $\mathrm{CFC}$ & -0.06 & & 0.03 & - & -0.02 & 0.14 & 0.03 & 0.32 & -0.18 & 0.10 & 0.02 & 0.04 & 0.07 & 0.01 & -0.01 & 0.04 \\
\hline EPS_ACC & -0.38 & 0.03 & & 0.10 & -0.02 & 0.00 & -0.02 & -0.01 & -0.02 & 0.01 & -0.02 & 0.08 & 0.13 & 0.11 & -0.02 & 0.09 \\
\hline CPS_ACC & -0.10 & - & 0.11 & & -0.01 & 0.01 & 0.04 & 0.00 & 0.00 & -0.02 & 0.02 & -0.03 & 0.02 & 0.02 & -0.03 & -0.02 \\
\hline ACCRUALS & 0.00 & 0.02 & -0.01 & 0.00 & & -0.15 & 0.04 & 0.11 & 0.29 & -0.10 & 0.01 & -0.03 & -0.01 & -0.02 & 0.02 & -0.04 \\
\hline ACCT_CHOICE & -0.03 & 0.13 & 0.00 & 0.02 & -0.17 & & 0.04 & 0.03 & -0.15 & 0.15 & -0.01 & 0.02 & 0.00 & 0.00 & 0.01 & 0.01 \\
\hline VOLATILITY & -0.07 & 0.04 & 0.01 & 0.03 & 0.27 & -0.05 & & -0.01 & -0.02 & -0.10 & 0.01 & -0.02 & 0.01 & -0.01 & 0.00 & -0.01 \\
\hline CAP_INT & -0.02 & 0.29 & 0.00 & 0.01 & 0.04 & 0.13 & -0.01 & & -0.18 & 0.05 & -0.01 & 0.00 & 0.00 & -0.01 & 0.00 & 0.00 \\
\hline ALTMAN_Z & -0.03 & -0.26 & -0.01 & 0.00 & 0.27 & -0.17 & $\mathbf{0 . 0 7}$ & -0.42 & & -0.10 & 0.00 & -0.02 & 0.00 & -0.03 & 0.01 & -0.03 \\
\hline SIZE & 0.01 & 0.11 & 0.02 & -0.02 & -0.18 & 0.16 & -0.22 & 0.16 & -0.20 & & 0.00 & 0.12 & 0.01 & 0.00 & 0.01 & 0.03 \\
\hline EXPERIENCE & 0.03 & 0.02 & -0.01 & 0.01 & 0.02 & -0.01 & 0.03 & 0.00 & 0.00 & 0.00 & & 0.03 & 0.22 & 0.01 & 0.09 & 0.31 \\
\hline BROK_SIZE & -0.04 & 0.04 & 0.08 & -0.03 & -0.02 & 0.02 & 0.00 & 0.00 & -0.02 & 0.13 & 0.04 & & 0.11 & 0.08 & 0.05 & 0.08 \\
\hline NUM_FIRMS & -0.30 & 0.08 & 0.11 & 0.02 & 0.06 & 0.01 & 0.14 & 0.06 & 0.06 & 0.03 & 0.23 & 0.12 & & 0.05 & -0.01 & 0.19 \\
\hline L_EPS_ACC & -0.04 & 0.01 & 0.10 & 0.02 & 0.00 & 0.00 & 0.00 & 0.00 & -0.01 & 0.01 & 0.01 & 0.08 & 0.05 & & -0.30 & 0.17 \\
\hline L_EPS_HOR & 0.02 & -0.01 & -0.02 & -0.03 & 0.00 & 0.01 & 0.00 & 0.00 & 0.01 & 0.01 & 0.10 & 0.06 & 0.00 & -0.28 & & -0.15 \\
\hline L_EPS_FREQ & -0.07 & 0.05 & 0.08 & 0.03 & 0.00 & 0.00 & 0.03 & 0.01 & -0.01 & 0.03 & 0.31 & 0.08 & 0.20 & 0.18 & -0.17 & \\
\hline
\end{tabular}

Notes to Table 2:

This table contains sample Pearson (Spearman) correlations above (below) the diagonal ( $\mathrm{N}=26,415$ for all correlations excluding CPS ACC; $\mathrm{N}=5,690$ for all correlations including CPS_ACC). Correlation coefficient estimates that are statistically different from zero at two-tailed p-value $<0.05$ are in bold. Variable definitions follow. $\mathrm{CFC}=\overline{\mathrm{A}}$ indicator variable taking the value of one if an analyst's cash flow forecast accuracy score is nonmissing during the calendar year, zero otherwise; TURNOVER = An indicator variable taking the value of one if the analyst is present on the $\mathrm{I} / \mathrm{B} / \mathrm{E} / \mathrm{S}$ database in a given calendar year, but not present in the next calendar year, zero otherwise. Remaining variables are defined in the notes to Table 1. 
TABLE 3: LIKELIHOOD OF CASH FLOW FORECAST ISSUANCE

Eq. (4): $\quad \operatorname{Prob}(\mathrm{CFC}=1)=\mathrm{G}\left(\beta_{0}+\beta_{1}\right.$ ACCRUALS $+\beta_{2}$ ACCT_CHOICE $+\beta_{3}$ VOLATILITY $+\beta_{4}$ CAP_INT $+\beta_{5}$ ALTMAN_Z $+\beta_{6}$ SIZE $+\beta_{7}$ EXPERIENCE $+\beta_{8}$ BROK_SIZE $+\beta_{9}$ NUM_FIRMS $+\beta_{10}$ L_EPS_ACC $+\beta_{11}$ L_EPS_HOR $+\beta_{12}$ L_EPS_FREQ)

\begin{tabular}{|c|c|c|c|c|c|c|c|}
\hline \multirow[t]{2}{*}{ Variable } & \multirow[t]{2}{*}{$\begin{array}{l}\text { Pred. } \\
\text { Sign }\end{array}$} & \multicolumn{4}{|c|}{ Coefficient Estimates (Std. Error) } & \multicolumn{2}{|c|}{$\begin{array}{c}\text { Marginal Effects } \\
\text { (Std. Error) }\end{array}$} \\
\hline & & Analyst-Lev & & Firm \& Analyst & Levels & & \\
\hline Intercept & & $\begin{array}{r}-1.4198 \\
(0.0567)\end{array}$ & & $\begin{array}{r}-2.5105 \\
(0.0987)\end{array}$ & & & \\
\hline ACCRUALS & + & & & $\begin{array}{r}-0.3127 \\
(0.1632)\end{array}$ & * & $\begin{array}{r}-0.0500 \\
(0.0261)\end{array}$ & $*$ \\
\hline ACCT_CHOICE & + & & & $\begin{array}{r}1.5051 \\
(0.0983)\end{array}$ & *** & $\begin{array}{r}0.2405 \\
(0.0157)\end{array}$ & *** \\
\hline VOLATILITY & + & & & $\begin{array}{r}0.0114 \\
(0.0029)\end{array}$ & *** & $\begin{array}{r}0.0018 \\
(0.0005)\end{array}$ & *** \\
\hline CAP_INT & + & & & $\begin{array}{r}0.2077 \\
(0.0057)\end{array}$ & *** & $\begin{array}{r}0.0332 \\
(0.0010)\end{array}$ & **** \\
\hline ALTMAN_Z & - & & & $\begin{array}{r}-0.0712 \\
(0.0036)\end{array}$ & *** & $\begin{array}{r}-0.0114 \\
(0.0005)\end{array}$ & *** \\
\hline SIZE & $?$ & & & $\begin{array}{r}0.1014 \\
(0.0090)\end{array}$ & *** & $\begin{array}{r}0.0162 \\
(0.0014)\end{array}$ & *** \\
\hline EXPERIENCE & $?$ & $\begin{array}{r}-0.0005 \\
(0.0005)\end{array}$ & & $\begin{array}{r}-0.0002 \\
(0.0006)\end{array}$ & & $\begin{array}{r}-0.0000 \\
(0.0001)\end{array}$ & \\
\hline BROK_SIZE & + & $\begin{array}{r}0.0019 \\
(0.0003)\end{array}$ & *** & $\begin{array}{r}0.0017 \\
(0.0004)\end{array}$ & **** & $\begin{array}{r}0.0003 \\
(0.0001)\end{array}$ & ${ }^{* * *}$ \\
\hline NUM_FIRMS & $?$ & $\begin{array}{r}0.0037 \\
(0.0004)\end{array}$ & *** & $\begin{array}{r}0.0051 \\
(0.0004)\end{array}$ & *** & $\begin{array}{r}0.0008 \\
(0.0001)\end{array}$ & *** \\
\hline L_EPS_ACC & + & $\begin{array}{r}-0.0001 \\
(0.0006)\end{array}$ & & $\begin{array}{r}0.0002 \\
(0.0007)\end{array}$ & & $\begin{array}{r}0.0000 \\
(0.0001)\end{array}$ & \\
\hline L_EPS_HOR & $?$ & $\begin{array}{r}-0.0012 \\
(0.0006)\end{array}$ & ** & $\begin{array}{r}-0.0012 \\
(0.0006)\end{array}$ & ** & $\begin{array}{r}-0.0002 \\
(0.0001)\end{array}$ & $*$ \\
\hline L_EPS_FREQ & + & $\begin{array}{r}0.0026 \\
(0.0005)\end{array}$ & *** & $\begin{array}{r}0.0023 \\
(0.0006)\end{array}$ & *** & $\begin{array}{r}0.0004 \\
(0.0001)\end{array}$ & *** \\
\hline Pseudo- $\mathrm{R}^{2}$ & & $1.0 \%$ & & $17.6 \%$ & & & \\
\hline
\end{tabular}




\section{Notes to Table 3:}

This table presents maximum likelihood estimations of Eq. (4) in the text $(\mathrm{N}=26,415)$. We tabulate the marginal effects assuming the remaining independent variables are held constant at their medians. For each variable in Eqs. (4), the estimated coefficient is presented with the coefficient standard error beneath in parentheses. We estimate the asymptotic variance covariance matrix of the marginal effects using the delta method (see Greene 2005, 674). The model pseudo- $\mathrm{R}^{2}$ is calculated as $1-\operatorname{lnL} / \ln \mathrm{L}_{0}$ where $\operatorname{lnL}=$ the maximized value of the $\log$-likelihood function and $\ln \mathrm{L}_{0}=$ the maximized value of the log-likelihood function for the model containing an intercept term only. Pseudo- $\mathrm{R}^{2}$ is bounded above by one and approaches zero from below (Greene, 2005). Variables are defined in the notes to Tables 1 and 2. significant at two-tailed $\mathrm{p}<0.01 ;{ }^{* *}$ significant at two-tailed $\mathrm{p}<0.05 ;{ }^{*}$ significant at two-tailed $\mathrm{p}<0.10$. 
TABLE 4: BIVARIATE PROBIT ESTIMATION RESULTS

Eq. (4): $\quad \operatorname{Prob}(\mathrm{CFC}=1)=\mathrm{G}\left(\beta_{0}+\beta_{1}\right.$ ACCRUALS $+\beta_{2}$ ACCT_CHOICE $+\beta_{3}$ VOLATILITY $+\beta_{4} \mathrm{CAP} \_\mathrm{INT}+\beta_{5} \mathrm{ALTMAN} Z+\beta_{6} \mathrm{SIZE}+\beta_{7} \mathrm{EXPERIENCE}+\beta_{8} \mathrm{BROK} \_\mathrm{SIZE}$ $+\beta_{9}$ NUM_FIRMS $+\beta_{10}$ L_EPS_ACC $+\beta_{11} L \_$EPS_HOR $+\beta_{12}$ L_EPS_FREQ)

Eq. (5): $\quad \operatorname{Prob}(\mathrm{TURNOVER}=1)=\mathrm{F}\left(\varphi_{0} \mathrm{CFC}+\varphi_{1} \times\left(\mathrm{CFC} \times \mathrm{EPS} \_\right.\right.$ACC $)$ $+\varphi_{2} \times\left(\mathrm{CFC} \times \mathrm{CPS} \_\mathrm{ACC}\right)+\varphi_{3} \times(1-\mathrm{CFC})+\varphi_{4} \times((1-\mathrm{CFC}) \times$ EPS_ACC $\left.)\right)$

Panel A: Bivariate SUR estimation

\begin{tabular}{|c|c|c|c|c|c|}
\hline \multirow{2}{*}{$\frac{\text { Variable }}{\text { Intercept }}$} & \multirow{2}{*}{$\begin{array}{c}\text { Pred. } \\
\text { Sign } \\
?\end{array}$} & \multicolumn{2}{|c|}{$\begin{array}{c}\text { Coefficient Estimates } \\
\text { (Std. Error) }\end{array}$} & \multicolumn{2}{|c|}{$\begin{array}{l}\text { Marginal Effects } \\
\text { (Std. Error) }\end{array}$} \\
\hline & & $\begin{array}{r}-2.4827 \\
(0.0988)\end{array}$ & & & \\
\hline ACCRUALS & + & $\begin{array}{r}-0.3770 \\
(0.1644)\end{array}$ & ** & $\begin{array}{r}-0.0154 \\
(0.0069)\end{array}$ & ** \\
\hline ACCT_CHOICE & + & $\begin{array}{r}1.5110 \\
(0.0979)\end{array}$ & $* * *$ & $\begin{array}{r}0.0617 \\
(0.0077)\end{array}$ & $* * *$ \\
\hline VOLATILITY & + & $\begin{array}{r}0.0117 \\
(0.0029)\end{array}$ & $* * *$ & $\begin{array}{r}0.0005 \\
(0.0001)\end{array}$ & $* * *$ \\
\hline CAP_INT & + & $\begin{array}{r}0.2059 \\
(0.0057)\end{array}$ & $* * *$ & $\begin{array}{r}0.0084 \\
(0.0009)\end{array}$ & $* * *$ \\
\hline ALTMAN_Z & - & $\begin{array}{r}-0.0700 \\
(0.0036)\end{array}$ & $* * *$ & $\begin{array}{r}-0.0029 \\
(0.0003)\end{array}$ & $* * *$ \\
\hline SIZE & $?$ & $\begin{array}{r}0.0969 \\
(0.0091)\end{array}$ & $* * *$ & $\begin{array}{r}0.0040 \\
(0.0006)\end{array}$ & $* * *$ \\
\hline EXPERIENCE & $?$ & $\begin{array}{r}-0.0006 \\
(0.0006)\end{array}$ & & $\begin{array}{r}-0.0000 \\
(0.00002)\end{array}$ & \\
\hline BROK_SIZE & + & $\begin{array}{r}0.0017 \\
(0.0004)\end{array}$ & $* * *$ & $\begin{array}{l}0.0001 \\
(0.00001)\end{array}$ & $* * *$ \\
\hline NUM_FIRMS & $?$ & $\begin{array}{r}0.0059 \\
(0.0005)\end{array}$ & $* * *$ & $\begin{array}{l}0.0002 \\
(0.00003)\end{array}$ & $* * *$ \\
\hline L_EPS_ACC & + & $\begin{array}{r}0.0001 \\
(0.0007)\end{array}$ & & $\begin{array}{l}0.0000 \\
(0.00002)\end{array}$ & \\
\hline L_EPS_HOR & $?$ & $\begin{array}{r}-0.0012 \\
(0.0006)\end{array}$ & * & $\begin{array}{r}-0.00004 \\
(0.00002)\end{array}$ & $*$ \\
\hline L_EPS_FREQ & + & $\begin{array}{r}0.0023 \\
(0.0006)\end{array}$ & $* * *$ & $\begin{array}{l}0.0001 \\
(0.00002)\end{array}$ & $* * *$ \\
\hline $\mathrm{CFC}$ & $?$ & $\begin{array}{r}0.1609 \\
(0.1159)\end{array}$ & & $\begin{array}{r}0.0046 \\
(0.0033)\end{array}$ & \\
\hline $\mathrm{CFC} \times$ EPS_ACC & - & $\begin{array}{r}-0.0314 \\
(0.0019)\end{array}$ & *** & $\begin{array}{r}-0.0009 \\
(0.0001)\end{array}$ & $* * *$ \\
\hline $\mathrm{CFC} \times$ CPS_ACC & - & $\begin{array}{r}-0.0023 \\
(0.0011)\end{array}$ & ${ }^{* *}$ & $\begin{array}{r}-0.0001 \\
(0.00003)\end{array}$ & ** \\
\hline $1-\mathrm{CFC}$ & $?$ & $\begin{array}{r}0.4805 \\
(0.0268)\end{array}$ & $* * *$ & $\begin{array}{r}0.0127 \\
(0.0012)\end{array}$ & $* * *$ \\
\hline$(1-$ CFC $) \times$ EPS_ACC & - & $\begin{array}{r}-0.0296 \\
(0.0006)\end{array}$ & $* * *$ & $\begin{array}{r}-0.0009 \\
(0.0001)\end{array}$ & $* * *$ \\
\hline $\begin{array}{l}\text { Pseudo- } \mathrm{R}^{2}(\text { Eq. }(4)) \\
\left.\text { Pseudo-R }{ }^{2} \text { (Eq. }(5)\right) \\
\rho=0.16(\text { two-tailed } \mathrm{p}<0.01)\end{array}$ & & $\begin{array}{l}17.6 \% \\
14.3 \%\end{array}$ & & & \\
\hline
\end{tabular}




\section{TABLE 4: BIVARIATE PROBIT ESTIMATION RESULTS (continued)}

Eq. (4): $\quad \operatorname{Prob}(\mathrm{CFC}=1)=\mathrm{G}\left(\beta_{0}+\beta_{1}\right.$ ACCRUALS $+\beta_{2}$ ACCT_CHOICE $+\beta_{3}$ VOLATILITY

$$
+\beta_{4} \text { CAP_INT }+\beta_{5} \text { ALTMAN_Z }+\beta_{6} \text { SIZE }+\beta_{7} \text { EXPERIENCE }+\beta_{8} \text { BROK_SIZE }
$$$$
+\beta_{9} \text { NUM_FIRMS }+\beta_{10} \text { L_EPS_ACC }+\beta_{11} \text { L_EPS_HOR }+\beta_{12} \text { L_EPS_FREQ) }
$$

Eq. (5): $\quad \operatorname{Prob}($ TURNOVER $=1)=\mathrm{F}\left(\varphi_{0} \mathrm{CFC}+\varphi_{1} \times(\mathrm{CFC} \times\right.$ EPS_ACC $)$

$$
\left.+\varphi_{2} \times(\text { CFC } \times \text { CPS_ACC })+\varphi_{3} \times(1-\text { CFC })+\varphi_{4} \times((1-\text { CFC }) \times \text { EPS_ACC })\right)
$$

\section{Panel B: Hypothesis test (in alternate form)}

\begin{tabular}{ll}
\hline Hypothesis test & Test statistic \\
\hline $\mathrm{H}_{2}: \varphi_{1}-\varphi_{2}<0$ & $\chi^{2}(1)=12.81^{* * *}$
\end{tabular}

\section{Notes to Table 4:}

Panel A contains maximum likelihood estimations of Eqs. (4) and (5) in the text using seemingly unrelated regression techniques that allow for across correlation in the equation disturbance terms $(\mathrm{N}=26,415)$. We tabulate the marginal effects assuming the remaining independent variables are held constant at their medians. For each variable in Eqs. (4) and (5), the estimated coefficient is presented with the coefficient standard error beneath in parentheses. We estimate the asymptotic variance covariance matrix of the marginal effects using the delta method (see Greene 2005, 674). Panel B contains the hypothesis test for $\mathrm{H}_{2}$. The number in parentheses following the $\chi^{2}$ statistic is the degrees of freedom. Variables are defined in the notes to Tables 1 and 2; the Pseudo- $\mathrm{R}^{2}$ measure is defined in the note to Table $3 .{ }^{* * *}$ significant at two-tailed $\mathrm{p}<0.01 ;{ }^{* *}$ significant at two-tailed $\mathrm{p}<0.05 ;^{*}$ significant at two-tailed $\mathrm{p}<0.10$. 


\section{TABLE 5: RELATIVE CASH FLOW FORECAST ACCURACY CONDITIONAL ON THE USEFULNESS OF CPS FORECASTS}

\begin{tabular}{|c|c|c|c|c|}
\hline \multirow[b]{2}{*}{ Firm-Level Variable } & \multicolumn{3}{|c|}{ Coefficient Estimates (Std. Error) } & \multirow{2}{*}{$\begin{array}{c}\chi^{2}(p \text {-value }) \\
\text { Difference Test }\end{array}$} \\
\hline & Above Median & & Below Median & \\
\hline ACCRUALS & $\begin{array}{r}-0.0057 \\
(0.0020)\end{array}$ & & $\begin{array}{r}-0.0011 \\
(0.0011)\end{array}$ & $\begin{array}{c}3.91 \\
(0.0470)\end{array}$ \\
\hline ACCT_CHOICE & $\begin{array}{r}-0.0052 \\
(0.0016)\end{array}$ & $* * *$ & $\begin{array}{r}-0.0002 \\
(0.0017)\end{array}$ & $\begin{array}{r}4.06 \\
(0.0439)\end{array}$ \\
\hline VOLATILITY & $\begin{array}{r}-0.0054 \\
(0.0022)\end{array}$ & ** & $\begin{array}{r}-0.0016 \\
(0.0014)\end{array}$ & $\begin{array}{r}3.85 \\
(0.0497)\end{array}$ \\
\hline CAP_INT & $\begin{array}{r}-0.0029 \\
(0.0012)\end{array}$ & ** & $\begin{array}{r}-0.0004 \\
(0.0014)\end{array}$ & $\begin{array}{r}1.45 \\
(0.2285)\end{array}$ \\
\hline ALTMAN_Z & $\begin{array}{r}-0.0025 \\
(0.0014)\end{array}$ & * & $\begin{array}{r}-0.0018 \\
(0.0012)\end{array}$ & $\begin{array}{r}1.32 \\
(0.2506)\end{array}$ \\
\hline
\end{tabular}

Panel B: Multivariate results: Model with all five above-median interaction terms

\begin{tabular}{|c|c|c|c|c|}
\hline $\mathrm{ABOVE}^{I}$ & $\begin{array}{r}\text { Coefficient Estimates of } \\
\mathrm{ABOVE}^{I} \times \mathrm{CFC} \times \mathrm{CPS} \mathrm{ACC} \\
(\text { Std. Error })\end{array}$ & & $\begin{array}{r}\text { Marginal Effects } \\
\text { (Std. error) }\end{array}$ & \\
\hline $\mathrm{ABOVE}^{\mathrm{ACCRUALS}}$ & $\begin{array}{r}-0.0021 \\
(0.0010)\end{array}$ & & $\begin{array}{r}-0.0004 \\
(0.0002)\end{array}$ & \\
\hline $\mathrm{ABOVE}^{\mathrm{ACCT} \_\mathrm{CHOICE}}$ & $\begin{array}{r}-0.0022 \\
(0.0011)\end{array}$ & ** & $\begin{array}{r}-0.0002 \\
(0.0001)\end{array}$ & $* *$ \\
\hline ABOVE ${ }^{\text {VOLATILITY }}$ & $\begin{array}{r}-0.0024 \\
(0.0012)\end{array}$ & ** & $\begin{array}{r}-0.0001 \\
(0.0001)\end{array}$ & $* *$ \\
\hline ABOVE ${ }^{\text {CAP_INT }}$ & $\begin{array}{r}-0.0028 \\
(0.0013)\end{array}$ & ** & $\begin{array}{r}-0.0001 \\
(0.0001)\end{array}$ & ** \\
\hline ABOVE ${ }^{\text {ALTMAN_Z }}$ & $\begin{array}{r}-0.0012 \\
(0.0016)\end{array}$ & & $\begin{array}{r}-0.0001 \\
(0.0001)\end{array}$ & \\
\hline Pseudo- $\mathrm{R}^{2}$ & $14.8 \%$ & & & \\
\hline
\end{tabular}




\section{Notes to Table 5:}

Panel A contains maximum likelihood estimations of Eqs. (4) and (5) in the text using seemingly unrelated regression techniques that allow for cross correlation in the equation disturbance terms $(\mathrm{N}=26,415)$. The bivariate probit estimation is carried out separately for the subsamples of firms above and below the median values of the following variables: ACCRUALS, ACCT_CHOICE, VOLATILITY, CAP_INT, and ALTMAN_Z. In this table we multiply ALTMAN_Z by negative one so that the above (below) median partitions correspond to more (less) financially distressed firms. For each sample partition, the coefficient estimate for CFC $\times$ CPS_ACC is presented with the standard error in parentheses. We test for across sample differences in the coefficient estimates using the $\chi^{2}$ test. Panel B contains maximum likelihood estimations of Eqs. (4) and (5) using seemingly unrelated regression techniques after simultaneously including five three-way interaction terms. We create five indicator variables to identify whether the variable of interest is above its sample median, $\mathrm{ABOVE}^{\mathrm{I}}$ where $\mathrm{I}=\{$ ACCRUALS,

ACCT_CHOICE, VOLATILITY, CAP_INT, or ALTMAN_Z $\}$. For example, ABOVE ${ }^{\text {ACCRUALS }}$ is an indicator variable equal to one (zero) if ACCRUALS is above (below) its sample median. We then include $\mathrm{ABOVE}^{\mathrm{I}}$ as a three-way interaction term, $\mathrm{ABOVE}^{\mathrm{I}} \times \mathrm{CFC} \times \mathrm{CPS} \_\mathrm{ACC}$, for each of the five variables of interest simultaneously. Hence, five three-way interaction terms are simultaneously added to Eq. (5). Coefficient estimates are presented with the standard error in parentheses. We tabulate the marginal effects assuming the remaining independent variables are held constant at their medians. We estimate the asymptotic variance covariance matrix of the marginal effects using the delta method (see Greene 2005, 674). Remaining variables are defined in the notes to Tables 1 and 2; the Pseudo- $\mathrm{R}^{2}$ measure in Panel B is defined in the note to Table 3. ${ }^{* * *}$ significant at two-tailed $\mathrm{p}<0.01 ;{ }^{* *}$ significant at two-tailed $\mathrm{p}<0.05 ;^{*}$ significant at two-tailed $\mathrm{p}<0.10$. 


\section{TABLE 6: RELATIVE CASH FLOW FORECAST ACCURACY CONDITIONAL ON THE NUMBER OF OTHER ANALYSTS ISSUING CPS FORECASTS}

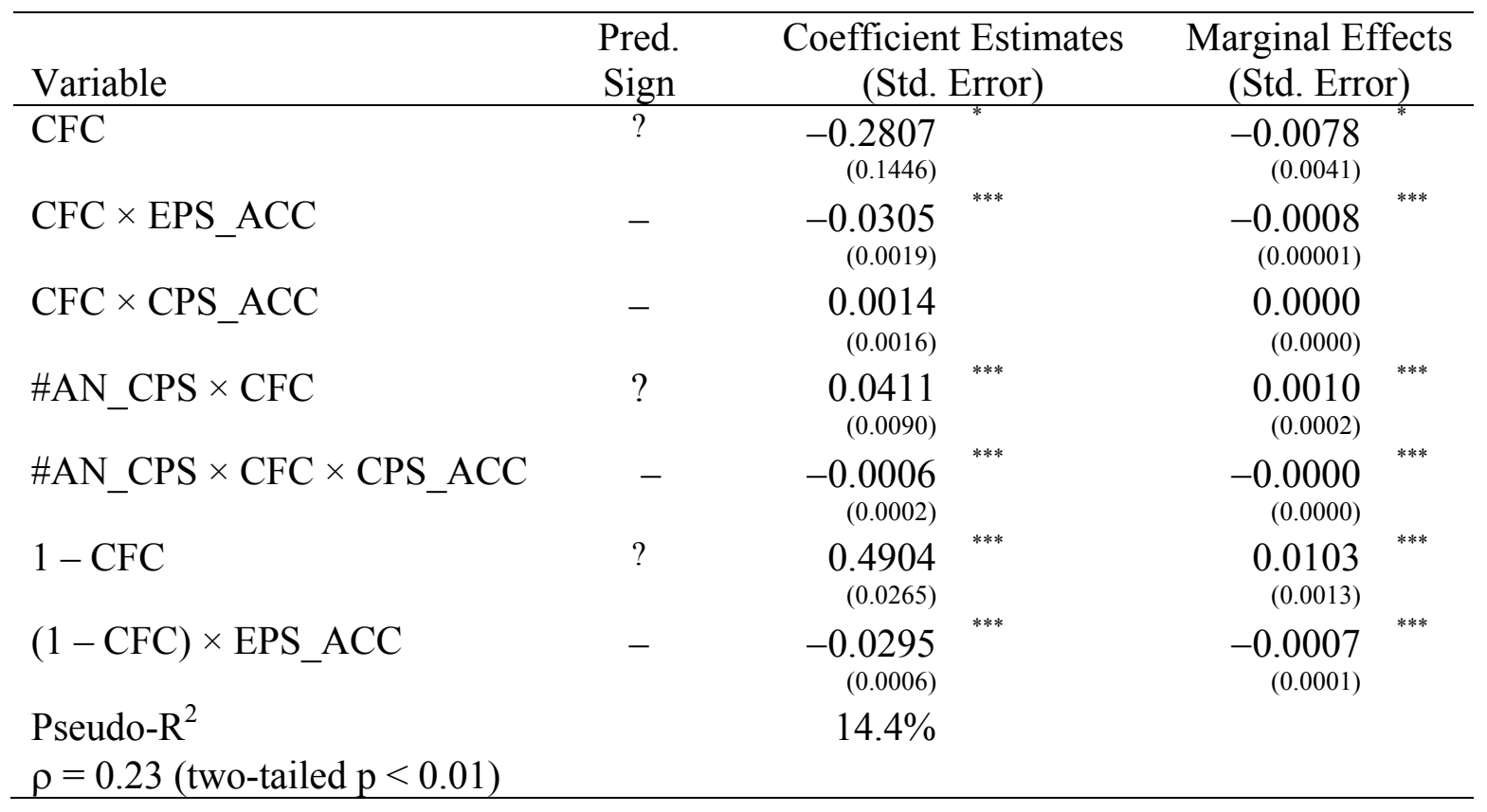

Notes to Table 6:

The table contains maximum likelihood estimations of Eqs. (4) and (5) in the text using seemingly unrelated regression (SUR) techniques that allow for cross correlation in the equation disturbance terms $(\mathrm{N}=26,415)$. Only Eq. (5), modified to include interaction terms with \#AN_CPS, is presented for brevity. \#AN_CPS is defined as the number of analysts providing at least one annual CPS forecast for the firm in the current calendar year (averaged across all firms for which the analyst issues one or more earnings or cash flow forecasts in the current calendar year). We tabulate the marginal effects assuming the remaining independent variables are held constant at their medians. For each variable the estimated coefficient is presented with the coefficient standard error beneath in parentheses. We estimate the asymptotic variance covariance matrix of the marginal effects using the delta method (see Greene 2005, 674). Remaining variables are defined in the notes to Tables 1 and 2; the Pseudo- $\mathrm{R}^{2}$ measure is defined in the note to Table $3 .{ }^{* * *}$ significant at two-tailed $\mathrm{p}<0.01 ;{ }^{* *}$ significant at two-tailed $\mathrm{p}<0.05 ;{ }^{*}$ significant at two-tailed $\mathrm{p}<0.10$. 


\section{APPENDIX: VARIABLE DEFINITIONS (Compustat data item numbers provided in parentheses, where applicable)}

\begin{tabular}{|c|c|}
\hline VARIABLE & DEFINITION \\
\hline TURNOVER & $\begin{array}{l}\text { An indicator variable equal to one if the analyst is present on the } \mathrm{I} / \mathrm{B} / \mathrm{E} / \mathrm{S} \\
\text { database in the current calendar year but not the next calendar year. }\end{array}$ \\
\hline $\mathrm{CFC}$ & $\begin{array}{l}\text { An indicator variable equal to one if an analyst's cash flow forecast accuracy } \\
\text { score is nonmissing during the calendar year, zero otherwise. }\end{array}$ \\
\hline \multicolumn{2}{|c|}{ FIRM-LEVEL VARIABLES } \\
\hline ACCRUALS & $\begin{array}{l}\text { The absolute value of net income before extraordinary items (data item \#18) } \\
\text { less operating cash flows (data item \#308) deflated by total assets (data item } \\
\# 6 \text { ) at the beginning of the fiscal year. If the numerator values are missing } \\
\text { we estimate accruals as the asset-deflated value of the change in working } \\
\text { capital less depreciation (data item \#14), where working capital = current } \\
\text { assets (data item \#4) - cash (data item \#1) - current liabilities (data item \#5) } \\
+ \text { debt in current liabilities (data item \# 34). Measured in the year before the } \\
\text { forecasted year and averaged across all firms followed by the analyst in a } \\
\text { given calendar year. }\end{array}$ \\
\hline ACCT_CHOICE & $\begin{array}{l}\text { An index ranging from zero to one, computed by assigning a value of one for } \\
\text { each firm's accounting choice that differs from the most prevalent method in } \\
\text { the firm's industry group (using Fama and French, } 1997 \text { industry } \\
\text { classifications). Accounting choices are: (i) inventory valuation; (ii) } \\
\text { investment tax credit; (iii) depreciation; (iv) successful-efforts versus full- } \\
\text { cost for firms in extraction industries; and (v) purchase versus pooling. The } \\
\text { score for the firm is obtained by summing the zero-one indicators and } \\
\text { deflating by the number of accounting choices in the industry (after } 2002 \text { we } \\
\text { ignore the purchase/pooling distinction). Measured in the year before the } \\
\text { forecasted year and averaged across all firms followed by the analyst in a } \\
\text { given calendar year. }\end{array}$ \\
\hline VOLATILITY & $\begin{array}{l}\text { The coefficient of variation of earnings for the firm, measured over the } \\
\text { sample period (1993-2005) and calculated as the standard deviation of net } \\
\text { income before extraordinary items deflated by the absolute value of the mean } \\
\text { value of earnings during the sample period. VOLATILITY is calculated by } \\
\text { averaging the firm-level measures across all firms followed by the analyst in } \\
\text { a given calendar year. }\end{array}$ \\
\hline CAP_INT & $\begin{array}{l}\text { The ratio of Gross Property, Plant, and Equipment (data item \#7) for the firm } \\
\text { deflated by net sales revenue at the beginning of the fiscal year (data item } \\
\# 12 \text { ). Measured in the year before the forecasted year and averaged across } \\
\text { all firms followed by the analyst in a given calendar year. }\end{array}$ \\
\hline
\end{tabular}




\section{APPENDIX: VARIABLE DEFINITIONS (continued) (Compustat data item numbers provided in parentheses, where applicable)}

\begin{tabular}{|c|c|}
\hline \multirow{2}{*}{\multicolumn{2}{|c|}{$\begin{array}{l}\text { VARIABLE DEFINITION } \\
\text { FIRM-LEVEL VARIABLES (continued) }\end{array}$}} \\
\hline & \\
\hline ALTMAN_Z & $\begin{array}{l}\text { The Altman } Z \text {-score (Altman, 1968), } Z \text {, for the firm at the beginning of the } \\
\text { fiscal year. } Z=1.2 \times((\text { Current assets }- \text { current liabilities }) / \text { Total Assets })+ \\
1.4 \times((\text { Retained earnings (data item } \# 36)) / \text { Total assets })+3.3 \times(\text { Earnings } \\
\text { before interest and taxes/Total assets })+0.6 \times(\text { Market value of equity/Book } \\
\text { value of liabilities })+1.0 \times(\text { Sales/Total assets). Lower } Z \text {-scores represent } \\
\text { poorer financial health. Measured in the year before the forecasted year and } \\
\text { averaged across all firms followed by the analyst in a given calendar year. }\end{array}$ \\
\hline SIZE & $\begin{array}{l}\text { The natural logarithm of the market value of equity for the firm (data item } \\
\# 25 \times \text { data item } \# 199 \text { ). Measured in the year before the forecasted year and } \\
\text { averaged across all firms followed by the analyst in a given calendar year. }\end{array}$ \\
\hline \multicolumn{2}{|c|}{ ANALYST-LEVEL VARIABLES } \\
\hline EXPERIENCE & $\begin{array}{l}\text { The number of years the analyst has issued an EPS forecast for the firm as of } \\
\text { the end of the previous calendar year. We begin calculating this measure as } \\
\text { of } 1978 \text {, the inception of the } \mathrm{I} / \mathrm{B} / \mathrm{E} / \mathrm{S} \text { database. EXPERIENCE is calculated } \\
\text { by averaging the firm-specific experience across all firms followed by the } \\
\text { analyst in the current calendar year. }\end{array}$ \\
\hline BROK_SIZE & $\begin{array}{l}\text { The number of analysts employed by the same broker as the analyst in the } \\
\text { current calendar year. Averaged across all firms followed by the analyst in } \\
\text { the current calendar year. }\end{array}$ \\
\hline NUM_FIRMS & $\begin{array}{l}\text { The number of firms for which the analyst issued EPS forecasts in the } \\
\text { current calendar year. Averaged across all firms followed by the analyst in } \\
\text { the current calendar year. We use EPS forecasts only to avoid inducing a } \\
\text { mechanical relation between this variable and the dependent variable. }\end{array}$ \\
\hline L_EPS_ACC & $\begin{array}{l}\text { Relative earnings-per-share forecasting accuracy, defined in Eqs. (1) and (3). } \\
\text { This measure is calculated for the previous year. Higher scores denote more } \\
\text { accurate earnings-per-share forecasts. Averaged across all firms followed by } \\
\text { the analyst in the current calendar year. }\end{array}$ \\
\hline L_EPS_HOR & $\begin{array}{l}\text { The number of calendar days between the latest EPS forecast made by the } \\
\text { analyst for the firm and the annual earnings announcement date obtained } \\
\text { from I/B/E/S. This measure is calculated for the previous year. Averaged } \\
\text { across all firms followed by the analyst in the current calendar year. }\end{array}$ \\
\hline L_EPS_FREQ & $\begin{array}{l}\text { The number of times the analyst issued an EPS forecast for the firm in the } \\
\text { previous calendar year. This measure is calculated for the previous year. } \\
\text { Averaged across all firms followed by the analyst in the current calendar } \\
\text { year. We use EPS forecasts only to avoid inducing a mechanical relation } \\
\text { between this variable and the dependent variable. }\end{array}$ \\
\hline EPS_ACC & $\begin{array}{l}\text { Relative earnings-per-share forecasting accuracy, defined in Eqs. (1) and (3). } \\
\text { Higher scores denote more accurate earnings-per-share forecasts. Averaged } \\
\text { across all firms followed by the analyst in the current calendar year. }\end{array}$ \\
\hline CPS_ACC & $\begin{array}{l}\text { Relative operating cash flow per share forecasting accuracy, defined in Eqs. } \\
\text { (2) and (3). Higher scores denote more accurate operating cash flow per } \\
\text { share forecasts. Averaged across all firms for which the analyst issues one or } \\
\text { more cash flow forecasts in the current calendar year. }\end{array}$ \\
\hline
\end{tabular}




\footnotetext{
${ }^{1}$ Another component of analyst reports, stock recommendations, is more difficult to gauge given the ambiguity
} regarding the horizon over which it pertains and coarseness in the recommendation scale (see, e.g., Francis, 1997). Mikhail, Walther, and Willis (1999) find no significant relation between turnover and the profitability of analysts' stock recommendations. So, we exclude it in our turnover specification.

${ }^{2}$ We motivate our prediction for $\mathrm{H}_{4}$ based on the normative prediction of relative performance evaluation (RPE). We then assess the extent to which we observe analyst labor outcomes that are consistent with an RPE-based prediction. We are unable to distinguish an RPE-based prediction for our results from statistical phenomena that could lead to reductions in measurement error due to an increase in the number of analysts in the reference group. We thank an anonymous reviewer for suggesting this possibility.

${ }^{3}$ Following Wu and Zang (2009), we: (i) collect all merger information in which the acquirer's primary two-digit SIC is 60 (commercial banks), 62 (securities firms), or 63 (insurance companies) and the target's primary SIC is 6211 ; and (ii) the target is a U.S. firm $100 \%$ owned by the acquirer after the merger.

${ }^{4}$ For each observation, I/B/E/S contains an analyst code and the last name and first initial to which that code corresponds. In all cases in which the last name and first initial were associated with multiple $\mathrm{I} / \mathrm{B} / \mathrm{E} / \mathrm{S}$ analyst codes in year $\mathrm{t}$ we checked the Nelson's Directory of Investment Research for years $\mathrm{t}-1, \mathrm{t}$, and $\mathrm{t}+1$ to determine whether this last name and first initial correspond to different analysts with the same last name and first initial or one analyst who has been incorrectly assigned multiple codes.

${ }^{5}$ The Thomson Financial Glossary (2004) indicates that Thomson Financial ensures earnings realizations are entered into the $\mathrm{I} / \mathrm{B} / \mathrm{E} / \mathrm{S}$ database on the same basis as the analysts' earnings forecasts. The documentation is silent regarding whether a similar adjustment is applied to cash flow actuals. Givoly, Hayn, and Lehavy $(2009,1886)$ state, "While no explanation is provided about the adjustments made to the actual cash flow amounts, $\mathrm{I} / \mathrm{B} / \mathrm{E} / \mathrm{S}$ representatives confirmed that this explanation [regarding adjustments to earnings realizations so that they are comparable to earnings forecasts] applies also to the actual cash flow data."

${ }^{6}$ Hong, Kubik, and Solomon (2000) rank analysts in each year and then average the ranks over a rolling three year period to reduce the likelihood that a particular analyst's rank is affected by extreme performance in one year. We do not implement this procedure because it would significantly reduce our sample size (given the relative paucity of cash flow forecasts). Moreover, we aggregate the accuracy rankings across all firms an analyst follows. This aggregation reduces the chance that an analyst with one large forecast error for a firm will earn a rank atypical of her forecasting performance.

${ }^{7}$ NUM FIRMS is aggregated across firms covered by the same analyst. Hence, the mean need not be close to 50 . Consider an example with 99 analysts covering 1 different firm each while another analyst covers all 99 firms. Thus, each of the 99 firms in the universe is covered by two analysts. The analyst covering all firms receives a score of 100 for each firm in her portfolio; the remaining 99 analysts earn a score of zero. Hence, the mean NUM_FIRMS for the 100 analysts is one.

${ }^{8}$ To reduce the potential effects of outliers on our results, we delete observations in the top and bottom $0.5 \%$ of the sample distribution for each continuous independent firm-level variable (ACCRUALS, VOLATILITY, CAP_INT, ALTMAN Z, SIZE). Our inferences are unaffected if we retain these observations.

${ }^{9}$ Comparing seven downloads of the I/B/E/S recommendation database between 2000 and 2007, Ljungqvist, Malloy, and Marston (LMM, 2009) document four types of changes affecting matched observations across the various annual downloads: alterations, deletions, additions, and anonymizations. The latter, referring to analyst identifiers present on one annual I/B/E/S download but not another, is most relevant to this study; such anonymizations might cause us to mistakenly label "anonymized" analysts as leaving the database. Based on conversations with the Commercial Support Team at Thomson Financial (the provider of I/B/E/S) we have learned that the problems identified by LMM did occur on the I/B/E/S database, but for the recommendation file only, not the earnings estimate files that we use. Thus, we have no reason to expect that any of the changes identified by LMM would affect our findings. Moreover, LMM conclude that post-2006 downloads of the IBES database are relatively free of the changes they document. Although our sample period ends in 2005, we downloaded the IBES data for our analysis in 2007 . Thus, we conclude that our sample data should be unaffected by the issues identified by LMM.

${ }^{10}$ Consistent with DeFond and Hung (2003), we define CFC as an indicator variable rather than the proportion of firms followed for which an analyst issues an operating cash flow forecast. We delete observations without a cash flow actual number because those observations cannot be coded as zero (a cash flow forecast was issued) and they cannot be coded as one (they are not included in the estimation of Eq. (5), which requires that cash flow accuracy be nonmissing). We delete observations for which there is only one analyst providing a cash flow forecast as we 
cannot calculate relative cash flow forecast accuracy in that case. Retaining these observations and setting $\mathrm{CFC}=0$ increases the sample to 28,092 observations; all results are unchanged.

${ }^{11}$ We model the decision to issue a cash-flow-per share (CPS) forecast, but not an earnings-per-share (EPS) forecast because almost all analysts issue EPS forecasts. To check this assumption, we gathered all annual EPS and CPS forecasts from I/B/E/S for 1993 to 2005. We required only that an analyst issue at least one annual EPS or CPS forecast for the current fiscal year for a firm. Given this sample, we calculated the percentage of analyst-year observations (the unit of analysis for our empirical models) for which an analyst issued a CPS forecast but not an EPS forecast. The percentage of observations ranged from a low of $0.08 \%$ in 1995 to $0.36 \%$ in 1997, supporting our assumption that there would be insufficient variation in the EPS forecasting decision to model that choice.

${ }^{12}$ We include lagged values of relative earnings-per-share forecast accuracy (L EPS ACC) in Eq. (4) for two reasons. First, as explained in section 3, the current EPS forecast accuracy is not available at the time analysts decide whether to issue cash flow forecasts. Second, Call, Chen, and Tong (2009) find that analysts' earnings forecasts issued with cash flow forecasts are more accurate than earnings forecasts not accompanied by cash flow forecasts. Hence, CFC and EPS_ACC would be endogenous. To mitigate this possibility, we used lagged EPS_ACC, L_EPS_ACC, instead. For consistency we measure forecast horizon and forecast frequency with lagged values, L_EPS_HOR and L_EPS_FREQ, respectively. Our inferences are unchanged if we include current, rather than lagged, measures of these variables in Eq. (4).

${ }^{13}$ For example, if TURNOVER is measured in 2008 then EPS_ACC and CPS_ACC in Eq. (5) are measured in 2007, CFC and L_EPS_ACC in Eq. (4) are measured in 2007 and 2006, respectively

${ }^{14}$ The coefficient estimate associated with CFC $\times$ EPS_ACC $(-0.0314)$ is not statistically different from the coefficient estimate associated with $1-$ CFC $\times$ EPS_ACC $(-0.0296)$; the $\chi^{2}(1)$ statistic comparing these estimates is 0.91 (two-tailed $\mathrm{p}>0.10$ ). Thus, there is no difference in the weight attached to relative earnings forecast accuracy for analysts who also issue cash flow forecasts compared to those who do not.

${ }^{15}$ We multiply ALTMAN_Z by negative one so that the above (below) median partitions correspond to more (less) financially distressed firms.

${ }^{16}$ We do not report the model pseudo- $\mathrm{R}^{2}$ measures in Table 5 Panel A because of the number of estimations presented. Those measures are comparable to the model fit statistics for Eqs. (4) and (5) presented in Table 4. 